\title{
Mechanisms of Action of TSHR Autoantibodies
}

\author{
Authors \\ J. Furmaniak, J. Sanders, R. Núñez Miguel, B. Rees Smith \\ Affiliation \\ FIRS Laboratories, RSR Ltd, Parc Ty Glas, Llanishen, Cardiff, UK
}

\section{Key words \\ - TSH receptor \\ - autoantibodies \\ - Graves' disease \\ - thyroid}

received 09.04 .2015 accepted 24.07.2015

\section{Bibliography DOI http://dx.doi.org/ 10.1055/s-0035-1559648 Horm Metab Res 2015; 47: 735-752 \\ (c) Georg Thieme Verlag KG Stuttgart . New York ISSN 0018-5043}

\section{Correspondence}

Dr. B. Rees Smith

FIRS Laboratories RSR Ltd

Parc Ty Glas

Llanishen

Cardiff CF14 5DU

UK

Tel.: + 44/29/20765550

Fax: + 44/29/2076 4575

firs@rsrltd.eclipse.co.uk

\section{Abstract}

$\nabla$

The availability of human monoclonal antibodies (MAbs) to the TSHR has enabled major advances in our understanding of how TSHR autoantibodies interact with the receptor. These advances include determination of the crystal structures of the TSHR LRD in complex with a stimulating autoantibody (M22) and with a blocking type autoantibody (K1-70). The high affinity of MAbs for the TSHR makes them particularly suitable for use as ligands in assays for patient serum TSHR autoantibodies. Also, M22 and K1-70 are effective at low concentrations in vivo as TSHR agonists and antagonists respectively. K1-70 has important potential in the treatment of the hyperthyroidism of Graves' disease and Graves'

\section{Introduction}

$\nabla$

The thyroid stimulating hormone receptor (TSHR) is a major autoantigen in Graves' disease [1-4]. Autoantibodies to the TSHR with thyroid stimulating activity are the cause of the hyperthyroidism of Graves' disease [1-4] while the rarer blocking type TSHR autoantibodies can cause hypothyroidism [1-4]. Patient sera can contain a mixture of both types of TSHR autoantibodies and changes in the overall activity of the TSHR autoantibodies in serum can occur and have been shown to lead to changes in thyroid function [5-9].

To date 4 high affinity human monoclonal autoantibodies (MAbs) to the TSHR with the characteristics of patient serum autoantibodies have been isolated from the peripheral blood lymphocytes of patients with autoimmune thyroid disease $[7,8,10,11]$. Two of these autoantibodies (M22 and K1-18) have thyroid stimulating (agonist) activity while the other 2 autoantibodies (K1-70 and 5C9) have thyroid stimulating blocking (antagonist) activity. In addition 5C9 acts as an ophthalmopathy. Small molecule TSHR antagonists described to date do not appear to have the potency and/or specificity shown by K1-70. New models of the TSHR ECD in complex with various ligands have been built. These models suggest that initial binding of TSH to the TSHR causes a conformational change in the hormone. This opens a positively charged pocket in receptorbound TSH which attracts the negatively charged sulphated tyrosine 385 on the hinge region of the receptor. The ensuing movement of the receptor's hinge region may then cause activation. Similar activation mechanisms seem to take place in the case of FSH and the FSHR and LH and the LHR. However, stimulating TSHR autoantibodies do not appear to activate the TSHR in the same way as TSH.

\section{Thyroid Stimulating Monoclonal Autoantibodies $\nabla$}

The first high affinity human monoclonal autoantibody to the TSHR (M22) was isolated and cloned over 40 years after the initial discovery that thyroid autoantibodies caused the hyperthyroidism of Graves' disease [10]. The source of M22 is a hybridoma prepared from the peripheral blood lymphocytes of a 19 year old hyperthyroid male with Graves' disease and high levels of TSHR autoantibodies (400U/l as measured by inhibition of TSH binding to the TSHR) [10]. In contrast, the source of the thyroid stimulating autoanti- 
body K1-18 is a hybridoma prepared from the peripheral blood lymphocytes of a 54 year old patient with hypothyroidism and high levels of TSHR autoantibodies (160U/l as measured by inhibition of TSH binding to the TSHR) $[7,8]$. This female donor had a history of hyperthyroidism followed by hypothyroidism. The patient's serum at the time of blood collection showed both inhibition of TSH stimulated cyclic AMP production and stimulation of cyclic AMP production in TSHR transfected $\mathrm{CHO}$ cells (CHO-TSHR) (i.e., had both TSHR agonist and antagonist activity) $[7,8]$.

Both M22 and K1-18 have high binding affinity for the TSHR; $5 \times 10^{10} \mathrm{l} / \mathrm{mol}$ and $0.7 \times 10^{10} \mathrm{l} / \mathrm{mol}$, respectively, which is in the range of the receptor binding affinities calculated for Graves' patient serum TRAbs $[7,8,10,16]$. M22 and K1-18 inhibit ${ }^{125}$ I-TSH binding to the TSHR in a dose dependant manner giving 80 and $72 \%$ inhibition at $100 \mathrm{ng} / \mathrm{ml}$ and 22 and $21 \%$ inhibition at $10 \mathrm{ng} /$ $\mathrm{ml}$, respectively. Both $\mathrm{M} 22$ and $\mathrm{K} 1-18$ effectively inhibit binding of each other and of patient serum TRAbs to the TSHR $[7,8,10]$. Furthermore, both MAbs are potent stimulators of cyclic AMP production at nanogram per ml concentrations with M22 IgG being more effective than K1-18 IgG while both antibodies are full agonists of the TSHR giving the same maximal stimulation of cyclic AMP production as TSH. In an experiment with CHO-TSHR cells, M22 and $\mathrm{K} 1-18$ at $10 \mathrm{ng} / \mathrm{ml}$ caused a $91.5 \times$ and $45.5 \times$ increase, respectively compared to basal levels of cyclic AMP and at $100 \mathrm{ng} / \mathrm{ml}$ the increase was $117.5 \times$ and $113.8 \times$ basal, respectively ( $\bullet$ Fig. 1). In contrast, previously reported stimulating human MAbs to the TSHR showed weak stimulation of the TSHR at microgram per $\mathrm{ml}$ concentrations. For example TRMo-2 [12] gave a maximum of 2 to $2.3 \times$ basal stimulation at 1.25 to $10 \mu \mathrm{g} /$ $\mathrm{ml}(\bullet$ Fig. 1). Furthermore, the recombinant thyroid stimulating antibodies B6B7 and 101-2 described by Akimizu et al. [13] gave maximal stimulation of $1.7 \times$ and $2 \times$ basal at optimum concentrations of $30 \mu \mathrm{g} / \mathrm{ml}$ and $15 \mu \mathrm{g} / \mathrm{ml}$, respectively, similar to the original hybridoma produced IgG. These levels of biological activity are not representative of the potency of patient serum TRAbs. In contrast, purified M22 IgG and K1-18 IgG were 3000 times and 10000 times more potent than their respective donor serum IgGs in inhibiting ${ }^{125} \mathrm{I}-\mathrm{TSH}$ binding to the TSHR. These potency figures contrast markedly with those in previous reports of human TSHR autoantibodies. For example, the blocking and the stimulating MAbs described by Valente et al. [14] and Kohn et al. [15] were of similar potency to the donor serum $\operatorname{IgG}$.

The TSHR shows amino acid sequence and structural similarities to the other glycoprotein hormone receptors; luteinising hormone receptor (LHR) and follicle stimulating hormone receptor (FSHR) [17-19]. The glycoprotein hormones TSH, LH and FSH show low level cross reactivity between their native receptors [20]. However, M22 IgG was unable to stimulate cyclic AMP production in either CHO cells expressing the LHR at $20000 \times$ the molar concentration of human chorionic gonadotropin (hCG) which caused clear stimulation of the LHR [21]. Furthermore CHO cells expressing the FSHR were not stimulated by M22 IgG at $100 \times$ the molar concentration of FSH which caused clear stimulation of the FSHR [21]. K1-18 has also been shown to be unable to stimulate cyclic AMP production in CHO cells expressing the FSHR at $100 \times$ the molar concentrations of FSH causing stimulation or in CHO expressing the LHR at $10000 \times$ molar concentrations of hCG causing stimulation.

Crystal structures of both the M22 Fab and the K1-18 Fab have been resolved to $1.65 \AA[22,23]$. The M22 crystal structure shows

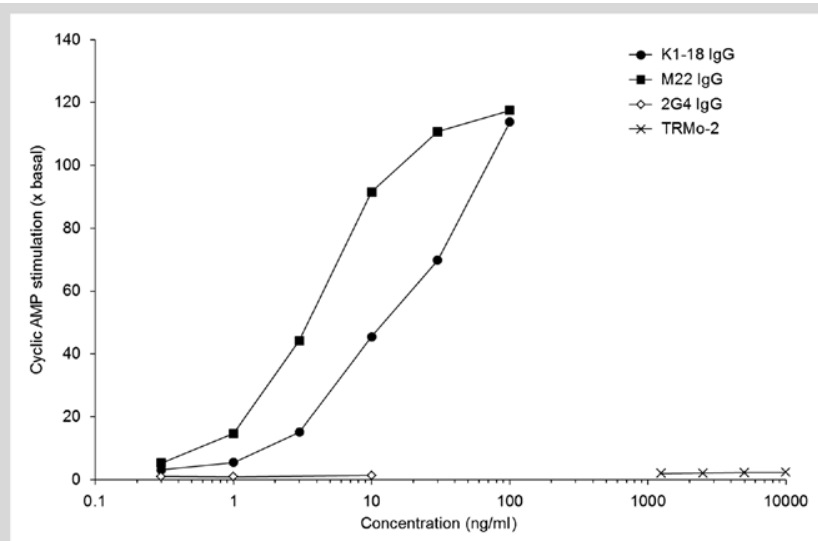

Fig. 1 Stimulation of cyclic AMP production in $\mathrm{CHO}$ cells expressing the TSHR by thyroid stimulating human monoclonal autoantibodies M22

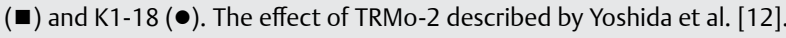
are shown as $(\mathrm{X})$ using data taken from [12]. A human monoclonal autoantibody to thyroid peroxidase $(2 \mathrm{G} 4 ; \diamond)[80]$ is shown as a control.

an N-linked glycosylation site at position Asn26 of the light chain (LC) with 1 molecule of $N$-acetyl-d-glucosamine linked to it. In contrast to M22, there are no sugar residues associated with the K1-18 Fab structure. The asymmetric unit of the M22 crystal contained a single Fab molecule with an elbow angle of $227.1^{\circ}$ and for K1-18 the asymmetric unit contained a single Fab molecule with an elbow angle of $169.1^{\circ}$. The elbow angle arrangements in the M22 structure resulted in M22 heavy chain (HC) protruding farther away from the Fab structure than M22 LC. In contrast the relative positions of the $\mathrm{HC}$ and $\mathrm{LC}$ in the K1-18 structure are more symmetrical.

$\mathrm{K} 1-18$ has $41.1 \%$ polar residues and $15.6 \%$ charged residues in the antigen binding region and a similar distribution of polar and charged residues is observed in the M22 structure $(41.9 \%$ polar residues and $14.1 \%$ charged residues). The surface of the M22 antigen binding site is dominated by basic patches on one side and acidic patches on the other side ( $\bullet$ Fig. 2 ). There are also many aromatic residues in the antigen-binding surface. Furthermore the surface of the variable region of M22 is irregular. The combining region of the K1-18 antigen-binding site ( $\bullet$ Fig. 2 ) is a highly irregular surface dominated by low potential basic patches on one side, acidic patches on the other side and a central positive patch. The surface of K1-18 Fab also contains many aromatic residues, the majority of which are contributed by the HC. In contrast to M22, there are no cavities on the surface of K1-18 (॰ Fig. 2). Fig. 2 also shows that the antigen-binding sites of the 2 thyroid stimulating human autoantibodies (K1-18 and M22) are mostly hydrophilic with no hydrophobic patches on their surfaces.

A crystal structure of the complex of the TSHR leucine-rich repeat domain (LRD) bound to M22 Fab has been solved at 2.55 ̊ resolution [24]. The TSHR LRD fragment in the structure consists of TSHR amino acids 22-260 (TSHR260). The TSHR260 in the crystal structure forms a slightly curved helical tube with the opposed concave and convex surfaces constructed from leucine-rich repeats (LRRs). The inner surface of the tube is lined with hydrophobic residues. The concave surface of the structure is made up by a 10-stranded beta-sheet while the convex surface is formed by 8 small strands forming beta sheets. All 5 glycosylation sites on the convex surface of the TSHR are glycosylated. The TSHR $\mathrm{N}$-terminal C31 and C41 are disulphide bonded ( $\bullet$ Fig. 3). 

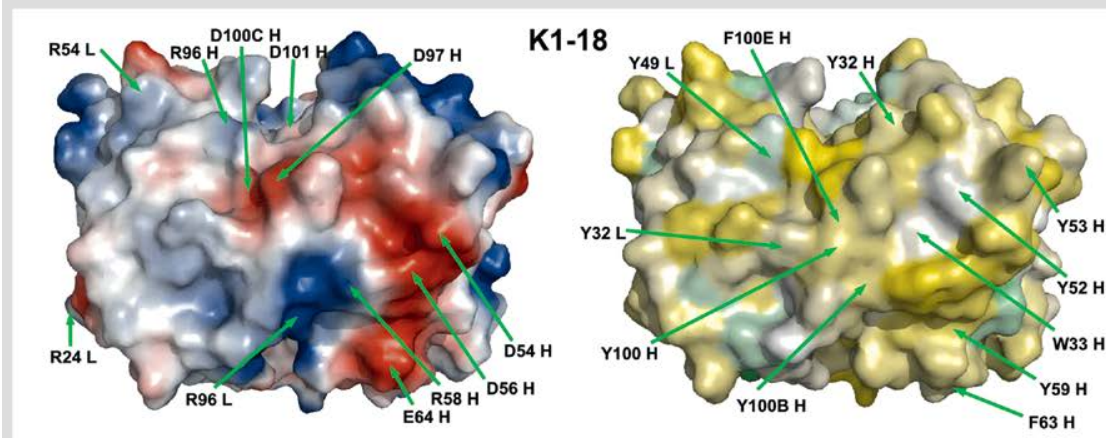

Fig. 2 The antigen binding surfaces of thyroid stimulating monoclonal autoantibodies (K1-18 and M22) and TSHR blocking monoclonal autoantibody (K1-70). The left panels show electrostatic surface potentials (positions of charged residues indicated) while the right panels show hydrophobic surfaces (positions of aromatic residues indicated). Negatively charged patches are shown in red and basic (positively charged) patches in blue. Hydrophilic patches are in yellow and hydrophobic patches in green. The figure was prepared in PyMOL [81]. Reproduced from Figure 1 of Núñez Miguel et al.

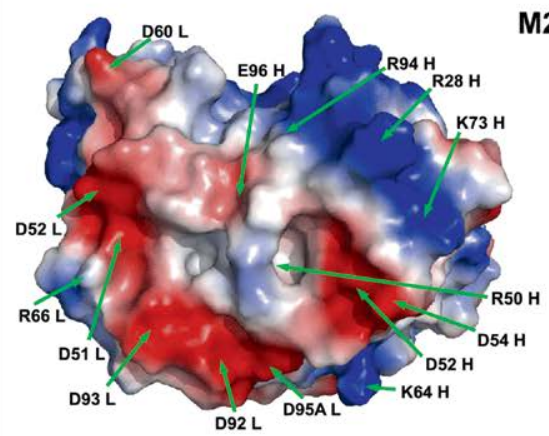

M22

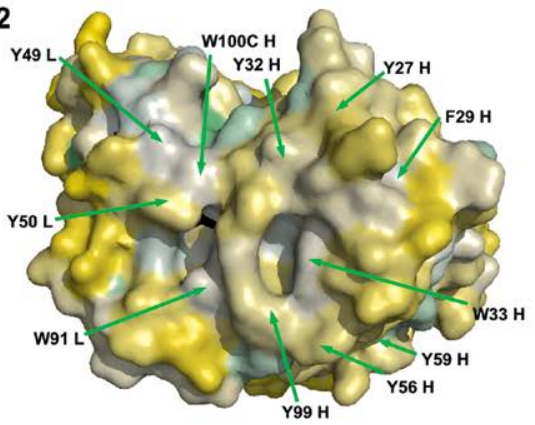

[23] (Copyright 2012 BioScientifica Ltd).
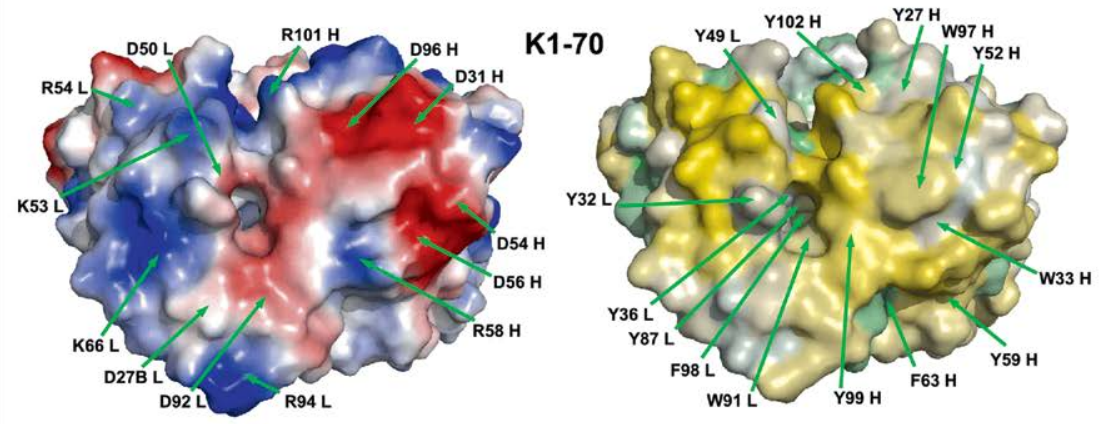

NEGATIVE

\begin{tabular}{l} 
HYOROPHILLC HYDROPHOBIC \\
\hline
\end{tabular}

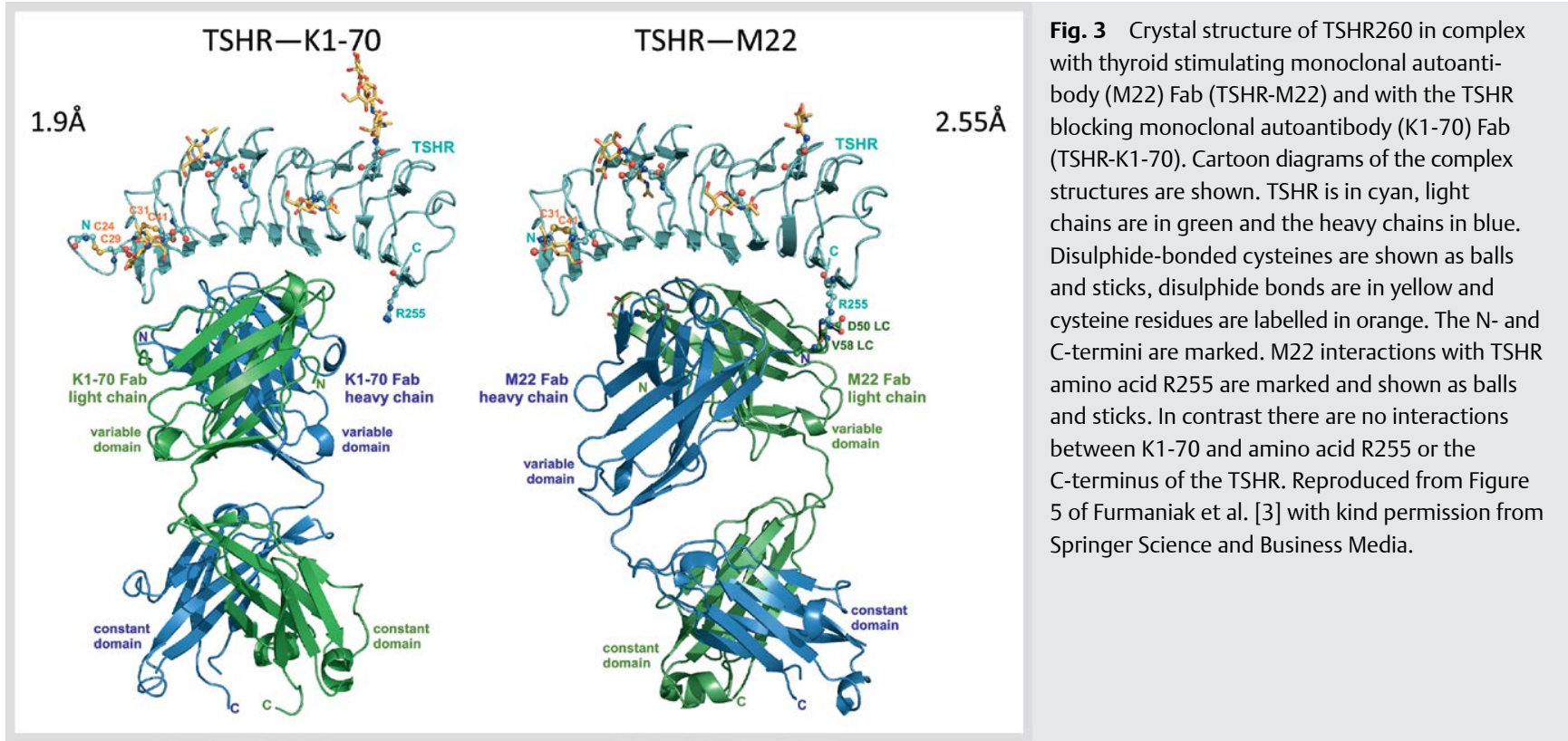


In the complex, M22 Fab embraces almost the entire TSHR260 concave surface. The TSHR residues from all 10 LRRs present in the structure form interactions with the HC and the LC of M22 Fab. M22 LC combines predominantly with the C-terminus whereas M22 HC combines predominantly with the N-terminus of the TSHR260 concave surface ( $\bullet$ Fig. 3 ). The area buried in the interface covers approximately $2500 \AA^{2}$ and there is a strong network of interactions including 22 hydrogen bonds and salt bridges, 17 polar interactions, and 14 hydrophobic contacts. The electrostatic surface potential of the TSHR260 concave surface shows predominantly negatively charged patches at the C-terminus and predominantly positively charged patches at the $\mathrm{N}$-terminus. In the complex the negatively charged patch on the surface of M22 combines with the positively charged region at the TSHR260 N-terminus while the positively charged patch of M22 surface combines with the TSHR260 C-terminal negatively charged region ( $\odot$ Fig. 4).

The binding arrangements in the TSHR260-M22 Fab complex were validated by mutation experiments [25]. In particular, TSHR mutations R80A, E107A, R109A, K129A, K183A, Y185A and R255A had an effect on M22 (but not TSH) stimulating activity and all these TSHR residues were found to form strong interactions with M22 in the solved structure of the complex. In particular, TSHR R255 was found to be critical for stimulation by all thyroid stimulating antibodies (including M22, serum TRAbs and stimulating MAbs produced in animals) but not by TSH. Further validation of the binding arrangements between TSHR260 and M22 Fab was provided by experiments involving amino acid mutations in M22 Fab itself [26].

The binding arrangements between the TSHR and M22 and between the TSHR and human TSH were analysed using the TSHR LRD-M22 complex structure (2.55 $\AA$ resolution) and a TSHR LRD-TSH complex built by basing it on the structure of the FSHR LRD-FSH complex (2.9 $\AA$ resolution) $[24,27,28]$. In the complexes both TSH and M22 position themselves in a very similar way with respect to the TSHR LRD. Both TSH and M22 embrace almost the entire concave surface of the TSHR LRD with accessible surface areas in the interface of $2514 \AA^{2}$ and $2533 \AA^{2}$ for TSHR-M22 and TSHR-TSH complexes, respectively. However, the network of interactions between the TSHR LRD and M22 is stronger than between the TSHR LRD and TSH and involves a greater number of hydrogen bonds and salt bridges with fewer hydrophobic interactions. Furthermore the gap volume index which is a measure of the strength with which the molecules interact was greater in the TSHR LRD-TSH complex compared to the TSHR LRD-M22 complex indicating that the interactions between the TSHR and TSH are weaker. These observations are consistent with the high binding affinity of M22 for the TSHR compared to the lower affinity of human TSH for the TSHR $[1,20,22]$. Both TSH and M22 interact with residues from all 10 beta strands in the TSHR LRD present in the structure. M22 LC and TSH $\beta$ chain form more interactions with the repeats at the $\mathrm{N}$ - and C-termini of the LRD than with the central part while M22 HC and TSH $\alpha$ chain interact mostly with the repeats in the central part of the LRD. M22 and TSH have similar electrostatic surface potentials in the areas that interact with the concave surface of the TSHR LRD ( $\odot$ Fig. 4). Furthermore, M22 HC and TSH $\alpha$ chain residues and M22 LC and TSH $\beta$ chain residues interact with the same sets of TSHR LRD residues, respectively. These observations indicate that M22 LC mimics the TSH $\beta$ chain in its interactions with the TSHR LRD while M22 HC mimics the interactions of the TSH $\alpha$ chain. This may be an example of molecular mimicry whereby evolutionary mechanisms drive the immune system to develop an autoantibody that can act like a hormone at 2 levels ie molecular interactions with the TSHR and biological activity. However, the nature of such evolutionary mechanisms which may be involved are not yet understood [28].

\section{Blocking Type Monoclonal Autoantibodies $\nabla$}

A hybridoma producing blocking type human monoclonal autoantibody 5C9 was isolated from the peripheral blood lymphocytes of a 27-year-old patient with postpartum hypothy-

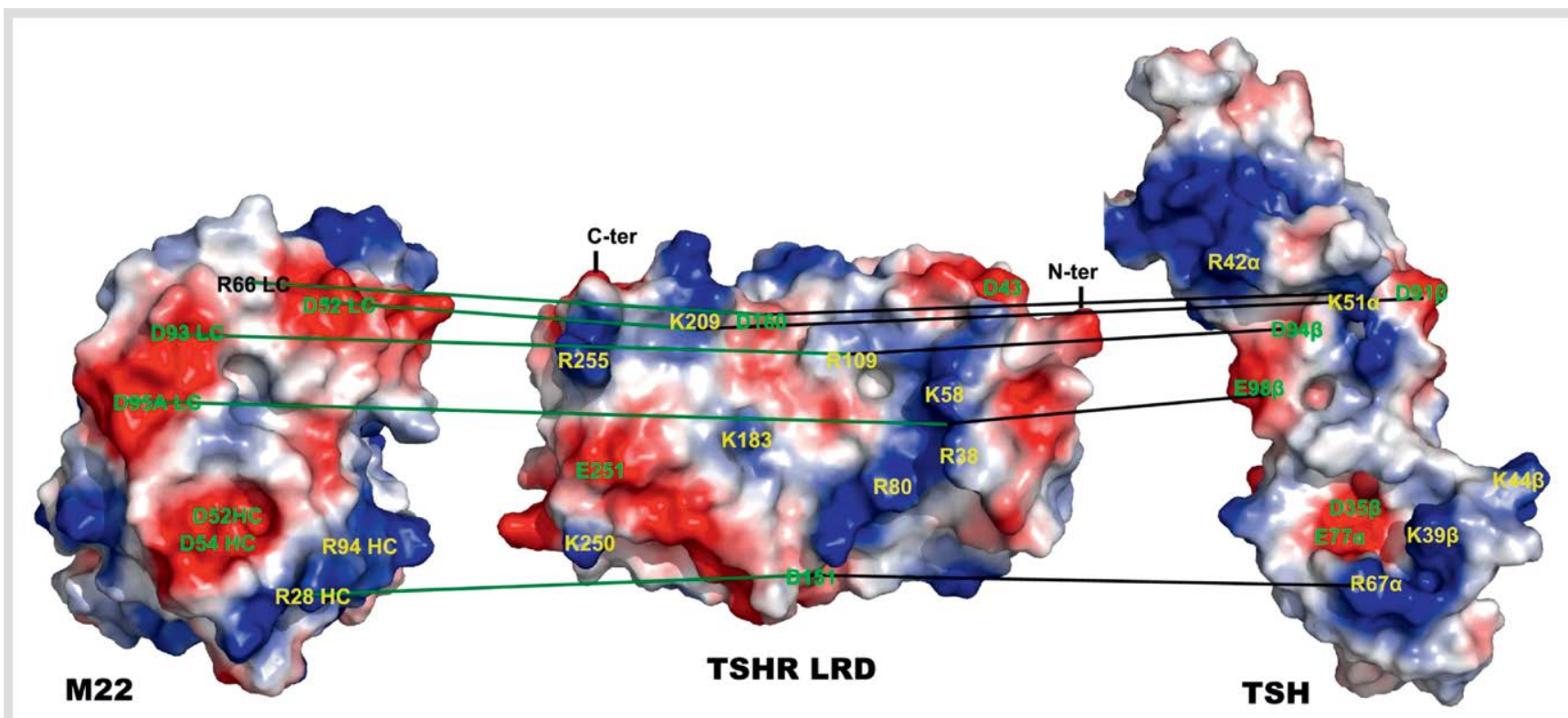

Fig. 4 Electrostatic surface potentials of the interacting surfaces of the TSHR LRD, M22 and TSH based on the crystal structure of the TSHR-M22 Fab complex and a model of the TSHR-TSH complex. Important interacting residues are indicated. The N- and C-termini are marked. Negative patches are shown in red and positive patches in blue. Horizontal lines show the interactions of charged residues on the TSHR with TSH (in black) and with M22 (in green). Reproduced from Figure 1 of Núñez Miguel et al. [28] (Copyright 2009 BioScientifica Ltd). 
roidism and high levels of TSHR autoantibodies (260U/l) as measured by inhibition of TSH binding to TSHR coated tubes [11]. Another blocking type human monoclonal autoantibody K1-70 was isolated from the same sample of patient peripheral blood lymphocytes as the thyroid stimulating monoclonal autoantibody K1-18 described above [7,8]. This proved unequivocally that both stimulating and blocking autoantibodies could exist in the serum of one patient at the same time.

K1-70 and 5C9 have similar high binding affinity for the TSHR $\left(4 \times 10^{10} \mathrm{l} / \mathrm{mol}\right)$ which is in the range of affinities calculated for patient serum TRAbs with blocking activity [7,8,11,16]. K1-70 and 5C9 are able to inhibit binding of ${ }^{125} \mathrm{I}-\mathrm{TSH}$ to the TSHR in a dose dependant manner with K1-70 being more effective than 5C9. Furthermore, K1-70 and 5C9 inhibit binding of each other and patient serum TRAbs to the TSHR $[7,8,11]$.

K1-70 and 5C9 are potent inhibitors of TSH stimulation of cyclic AMP production in CHO-TSHR cells $[7,8,11]$ and are active at nanogram/mL concentrations. In in vitro experiments K1-70 and 5C9 IgGs inhibited TSH induced cyclic AMP production by 61.6 and $62.3 \%$ at $50 \mathrm{ng} / \mathrm{ml}$ and by 86.9 and $81.6 \%$ at $100 \mathrm{ng} / \mathrm{ml}$, respectively. Neither autoantibody showed any stimulating activity over a range of concentrations indicating that both MAbs are pure antagonists.

Yoshida et al. [12] have also reported the production of blocking type TSHR MAbs by hybridomas obtained from patient lymphocytes. However, the MAbs they describe are far less potent than K1-70 and 5C9. Also, blocking type MAbs produced by patient peripheral blood lymphocytes [29] and expressed as recombinant IgGs have been described [30]. However, they had low affinity for the TSHR, inhibited TSH binding weakly or not at all and were weak blockers of TSH stimulated cyclic AMP production (e.g., $100 \mu \mathrm{g} / \mathrm{ml}$ IgG gave $67 \%$ inhibition [30]). Another laboratory has reported the isolation of B cell lines producing IgGs with weak TSH blocking activity but these IgGs were unable to inhibit TSH binding to the receptor [31]. Consequently, these antibodies did not resemble K1-70 or the blocking type TSHR autoantibodies usually found in patient sera.

K1-70 and 5C9 IgGs are potent inhibitors (Ic50 25 ng/ml; 175 $\mathrm{pM}$ ) of the stimulation of cyclic AMP production by Graves' patient sera $[7,8,11]$. The stimulating activity of $15 / 15$ sera tested was reduced to near unstimulated levels in the presence of K1-70 IgG in one study [8]. In the same study, 5C9 IgG inhibited stimulation by $14 / 15$ of the sera to near unstimulated levels and had no effect on $1 / 15$ sera [8]. In a second study (with different sera), 5C9 was able to inhibit the stimulation of cyclic AMP production by 15/16 Graves' patient sera to near unstimulated levels, however, in the case of serum from the one patient not inhibited to near unstimulated levels by 5C9 the inhibition was about $50 \%$ [11]. This is in agreement with previous studies suggesting that although stimulating autoantibodies in different patient sera interact with the same region of the TSHR there are differences in the actual contact amino acids involved $[7,8,11,25]$. Therefore, although K1-70 and 5C9 are effectively able to inhibit binding of one another to the TSHR these results suggest that there are subtle differences in the epitopes on the TSHR recognised by the 2 monoclonal antibodies.

The human monoclonal autoantibody 5C9 is able to reduce the basal constitutive activity of the TSHR giving $71 \%$ inhibition of basal levels of cyclic AMP production in TSHR-CHO cells at $1 \mu \mathrm{g}$ / $\mathrm{ml}$. In contrast K1-70 has no effect on the constitutive activity of the TSHR [11]. The antibody 5C9 was also able to reduce the constitutive activity of TSHRs with activating mutations S281I (in the TSHR extracellular domain), I568T (extracellular loop 2) and A623I (intracellular loop 3 ) by 60,74 , and $43 \%$, respectively, at $1 \mu \mathrm{g} / \mathrm{ml}[2,3,11]$. Higher concentrations of 5C9 $\operatorname{IgG}$ up to $100 \mu \mathrm{g}$ caused no further decrease in basal cyclic AMP levels in these experiments. A detailed comparison of 5C9 and K1-70 is shown in 0 Table 1.

Both the TSHR blocking monoclonal antibodies (5C9 and K1-70) were highly specific for the TSHR and showed no inhibition of FSH induced stimulation of cyclic AMP production in CHO cells expressing the human FSHR at 0.01 to $100 \mu \mathrm{g} / \mathrm{ml}$ of $\mathrm{IgG}$. Furthermore they showed no inhibition of LH induced stimulation of cyclic AMP production in CHO cells expressing the LHR at 0.01 to $100 \mu \mathrm{g} / \mathrm{ml}$ of IgG. Therefore, similar to M22, K1-18 and patient serum TRAbs they showed no cross reactivity with the FSHR or LHR.

The crystal structure of K1-70 Fab was determined at $2.22 \AA$ resolution [32]. Each crystal unit consists of 2 Fab molecules which have different structures (i.e., are not symmetrical) because of different elbow angles $\left(145.5^{\circ}\right.$ and $163.1^{\circ}$ ) [32]. The structure of K1-70 is that of a standard Fab fragment with no glycosylation. There are $40.4 \%$ polar residues and $14.6 \%$ charged residues on the antigen binding site surface similar to that observed for the structures of the stimulating autoantibodies K1-18 and M22 [32].

The surface of the K1-70 antigen binding site ( $\odot$ Fig. 2 ) is dominated by acidic patches on one side and basic patches on the other. The surface of K1-70 Fab also contains aromatic residues. The surface of the combining site is highly irregular with a cavity at the centre surrounded mostly by aromatic residues.

The 5C9 Fab fragment structure was modelled [2] and this showed that 5C9 was a typical Fab structure. However, the HC CDR 3 of 5C9 is 18 amino acids long and is expected to protrude outward from the $V$ domain. It contains a 3 amino acid insertion and a 6 amino acid insertions between the $\mathrm{V} / \mathrm{D}$ and $\mathrm{D} / \mathrm{J}$ regions, respectively. It also contains the CX4C motif of the D2-2 germline in which the 2 cysteine residues form an internal disulphide bond for loop stability. The electrostatic potential surface of 5C9 is mainly positive with only a small negative patch centred on Asp61 (HC). The antibody 5C9 has few charged amino acids ( 5 residues) and 8 aromatic residues in its combining site therefore most of the combining surface has an overall low electrostatic potential ( $\bullet$ Fig. 5). Overall the electrostatic potential surface of 5C9 is less charged than K1-70 and the HC CDR 3 protrudes further out of the combining surface and these differences in the topography of its antigen binding site may be related to the ability of 5C9 to block TSHR basal activity $[2,3,11]$.

The TSHR260-K1-70 Fab complex structure was solved at $1.9 \AA$ resolution [32] compared to the $2.55 \AA$ resolution for the TSHR260-M22 Fab structure. The higher resolution of the TSHR260-K1-70 Fab complex revealed the disulphide bonding arrangement at the TSHR N-terminus in that C24 is bonded with C29 and C31 is bonded with C41. Consequently in the TSHR the $1^{\text {st }}$ and the $2^{\text {nd }}$ cysteines and the $3^{\text {rd }}$ and the $4^{\text {th }}$ cysteines are bonded and form the N-terminal cap of the LRD. These arrangements are different to those in the FSHR [27].

The binding arrangements between the TSHR260 and K1-70 Fab are remarkably similar to those with M22 (and TSH) (๑ Fig. 3). However, K1-70 Fab is positioned more N-terminally on the TSHR LRD than M22 Fab and is bound at an approximate rotation of $155^{\circ}$ with respect to the position of M22 Fab. Furthermore the orientation of K1-70 and M22 Fab HCs and LCs are opposite ( $\odot$ Fig. 3). The area buried in the K1-70 Fab binding interface with TSHR2 60 covers $2565 \AA^{2}$ and this is similar to that observed 
Table 1 Summary of properties of human MAbs to the TSHR.

\begin{tabular}{|c|c|c|c|c|}
\hline & \multicolumn{2}{|l|}{ Stimulatory (agonist) } & \multicolumn{2}{|l|}{ Blocking (antagonist) } \\
\hline & M22 & K1-18 & $5 C 9$ & $\mathrm{~K} 1-70$ \\
\hline Isotype & $\lg 1 \lambda$ & $\lg G 1 \mathrm{\kappa}$ & $\lg G 1 \mathrm{k}$ & $\operatorname{lgG} 1 \lambda$ \\
\hline Binding affinity for the TSHR & $5 \times 10^{10} \mathrm{l} / \mathrm{mol}$ & $0.7 \times 10^{10} \mathrm{I} / \mathrm{mol}$ & $4 \times 10^{10} \mathrm{l} / \mathrm{mol}$ & $4 \times 10^{10} \mathrm{l} / \mathrm{mol}$ \\
\hline $\begin{array}{l}\text { Inhibition of TSH binding to the } \\
\text { TSHR }\end{array}$ & $80 \%$ at $100 \mathrm{ng} / \mathrm{ml}$ & $72 \%$ at $100 \mathrm{ng} / \mathrm{ml}$ & $35 \%$ at $100 \mathrm{ng} / \mathrm{ml}$ & $91 \%$ at $100 \mathrm{ng} / \mathrm{ml}$ \\
\hline Effect on TSHR activity & $\begin{array}{l}\text { Increases cyclic AMP } \\
\text { production in CHO- } \\
\text { TSHR cells } 92 \times \text { basal } \\
\text { at } 10 \mathrm{ng} / \mathrm{ml}\end{array}$ & $\begin{array}{l}\text { Increases cyclic AMP } \\
\text { production in CHO- } \\
\text { TSHR cells } 46 \times \text { basal } \\
\text { at } 10 \mathrm{ng} / \mathrm{ml}\end{array}$ & $\begin{array}{l}\text { Inhibition of TSH induced cyclic AMP } \\
\text { production in CHO-TSHR cells } 62 \% \\
\text { at } 50 \mathrm{ng} / \mathrm{ml}^{\mathrm{a}}\end{array}$ & $\begin{array}{l}\text { Inhibition of TSH } \\
\text { induced cyclic AMP pro- } \\
\text { duction in CHO-TSHR } \\
\text { cells } 62 \% \text { at } 50 \mathrm{ng} / \mathrm{ml}^{\mathrm{a}}\end{array}$ \\
\hline $\begin{array}{l}\text { Effect on TSHR constitutive (basal) } \\
\text { cyclic AMP levels }\end{array}$ & none & none & $\begin{array}{l}\text { Inhibition of basal levels of cyclic } \\
\text { AMP in CHO-TSHR cells ( } 71 \% \text { at } \\
1 \mu \mathrm{g} / \mathrm{ml} \text { ). Reduction of constitutive } \\
\text { activity of TSHR activating mutations } \\
\text { S281I, I568T and A623I by } 60,74 \text { and } \\
43 \% \text { respectively at } 1 \mu \mathrm{g} / \mathrm{ml}\end{array}$ & none \\
\hline $\begin{array}{l}\text { Inhibition of human MAbs binding } \\
\text { to the TSHR }\end{array}$ & K1-18, 5C9, K1-70 & $\mathrm{M} 22,5 \mathrm{C}, \mathrm{K} 1-70$ & $\mathrm{M} 22, \mathrm{~K} 1-18, \mathrm{~K} 1-70$ & $\mathrm{M} 22, \mathrm{~K} 1-18,5 \mathrm{C} 9$ \\
\hline $\begin{array}{l}\text { Inhibition of mouse thyroid stimu- } \\
\text { lating MAbs binding to the TSHR }\end{array}$ & Yes & Yes & Yes & Yes \\
\hline $\begin{array}{l}\text { Inhibition of binding to the TSHR by } \\
\text { patient serum TRAbs }\end{array}$ & Yes & Yes & Yes & Yes \\
\hline Molecular structure & Solved $1.65 \AA$ & Solved $1.65 \AA$ & Modelled & Solved $2.22 \AA$ \\
\hline Complex with the TSHR LRD & Solved $2.55 \AA$ & Modelled & Modelled & Solved $1.9 \AA$ \\
\hline $\begin{array}{l}\text { Interaction with the LRRs of the } \\
\text { TSHR LRD }\end{array}$ & $\begin{array}{l}\text { LRR } 1-10 \text { concave } \\
\text { surface of LRD }\end{array}$ & $\begin{array}{l}\text { LRR } 1-10 \text { concave } \\
\text { surface of LRD }\end{array}$ & $\begin{array}{l}\text { LRR 1-10 concave surface overlap- } \\
\text { ping the convex surface at the } \\
\text { C-terminal end of the LRD }\end{array}$ & $\begin{array}{l}\text { LRR } 1-8 \text { concave } \\
\text { surface of LRD }\end{array}$ \\
\hline Mimics TSH binding to the TSHR & Yes & Yes & No & No \\
\hline
\end{tabular}

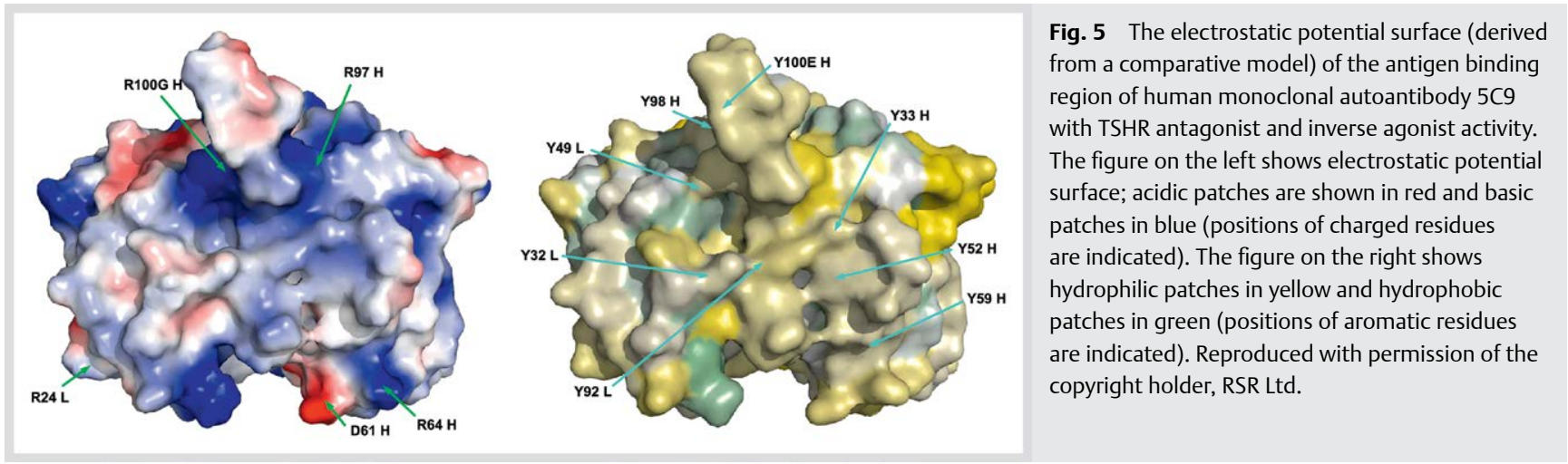

for M22 and for TSH in complex with the TSHR. There are 25 hydrogen bonds and salt bridges, 19 water-mediated hydrogen bonds, 11 polar interactions and 19 hydrophobic contacts in the K1-70-TSHR complex. The electrostatic potential surface of the interacting faces of TSHR260 and K1-70 Fab shows polarity in terms of charge distribution. In the complex, the TSHR260 areas with predominantly negative charge combine with the positively charged areas on the K1-70 LC binding surface and the positively charged area on TSHR260 combines with the negative patches on the K1-70 HC surface. The charge contributions from the HC and LC on the antigen binding surface of M22 are opposite [23, 24,32]. K1-70 Fab binds more towards the N-terminus of the TSHR260 concave surface than M22 Fab with the K1-70 interactions occurring between TSHR D36 and D203. In contrast, M22 Fab interactions span the entire concave surface between TSHR D36 and N256 [23,24,32]. K1-70 Fab interacts with TSHR residues from LRR 1-7 and there is only one interaction with repeat 8 . In contrast, M22 Fab interacts with residues from LRR 1-10 [23, 24,32].
Mutation experiments validated the binding arrangements observed in the TSHR260-K1-70 complex. In particular, TSHR mutations K58A, I60A, E61A, Y82A, R109A and K183A had an inhibiting effect on K1-70's ability to block TSH stimulation of cyclic AMP production in CHO-TSHR cells in agreement with the interactions with K1-70 observed in the structure [32]. Furthermore, mutation of K1-70 HC W97A and HC N100A, LC R94D, HC Y99A and HC N32A seen to be involved in the interactions with the TSHR260 in the crystal structure, resulted in the loss of the ability of K1-70 Fab to inhibit TSH-induced stimulation of cyclic AMP production [32].

\section{Similarities and Differences Between Stimulating and Blocking MAbs} $\nabla$

Human TSHR MAbs we have isolated to date are characterised by high binding affinity for the TSHR and both the stimulating and 
the blocking MAbs are biologically active at nmol/l concentrations. Furthermore, these stimulating and these blocking MAbs inhibit binding of each other, of TSH, of thyroid stimulating TSHR MAbs produced in experimental animals and of TSHR blocking MAbs produced in experimental animals to the TSHR [1$3,7,8,10,11]$. Also, patient sera TRAbs inhibit the binding of all these MAbs to the TSHR $[1-3,7,8,10,11]$. This suggests that the binding sites on the TSHR for both types of TSHR MAbs (i.e., stimulating and blocking) and patient serum TRAbs are overlapping although there may be discrete differences. Overall, the 4 human TSHR MAbs to the TSHR described here are representative of patient serum TRAbs.

Hybridomas producing 2 different TSHR autoantibodies K1-18 and $\mathrm{K} 1-70$ were isolated from the same sample of peripheral blood lymphocytes from a patient with hypothyroidism $[7,8]$. Analysis of the $\mathrm{V}$ regions of K1-18 and K1-70 indicates that the 2 antibodies (K1-18: stimulating and K1-70: blocking) have evolved separately from each other and must have originated from different $B$ cell clones [8]. Isolation of these 2 MAbs (K1-18 and K1-70) with different biological activities (stimulating and blocking) from the same blood sample provides the first direct evidence that TRAbs with different activities can be present in patients at the same time. This is consistent with observations that in some patients the symptoms of hyper- and hypothyroidism vary over time [5-9]. Takasu and Matsushita have shown that in a few patients, changes in clinical presentation of hypothyroidism to hyperthyroidism (and vice versa) were associated with changes in serum TRAb activities from blocking to stimulating and vice versa, respectively [33]. Consequently, clinical symptoms can depend sometimes on the relative concentrations and activities of blocking and stimulating TRAbs at any one time. The interaction of TSHR expressed on thyrocytes with TSH itself may also contribute to the clinical presentation. Finally, the ability of the thyroid gland affected by autoimmune destruction or inflammation to respond to the stimulating activities of TRAbs or TSH is critical for thyroid hormone secretion. Understanding how different factors may affect thyroid function in TRAb positive patients should be helpful in the clinical management of patients with autoimmune thyroid disease.

Some of the experimentally produced animal MAbs described in the literature have similar characteristics to the human MAbs to the TSHR described here. Mouse or hamster stimulating MAbs or mouse blocking MAbs reported from our own and some other laboratories are characterised by high binding affinity to the TSHR comparable to the human MAbs and have biological activities at very low concentrations [34-40]. For example RSR-B2 is a mouse TSHR MAb (IgG2b, kappa) with potent TSH binding inhibiting and TSHR antagonist activities [37]. RSR-B2 binding affinity for the TSHR is $2 \times 10^{10} \mathrm{l} / \mathrm{mol}$ and at $100 \mu \mathrm{g} / \mathrm{ml} \mathrm{RSR-B2}$ completely inhibits TSH-stimulated cAMP production in $\mathrm{CHO}-$ TSHR cells. Furthermore, RSR-B2 is an effective inhibitor of binding of both thyroid stimulating and TSHR blocking human MAbs to the TSHR. Furthermore, patient serum TRAbs inhibit binding of ${ }^{125}$ I-labelled RSR-B2 to the TSHR $[2,25,37]$. RSR-B2 mimics the binding and the biological activity of human TSHR blocking MAbs K1-70 and 5C9 with the exception that only 5C9 has an effect on TSHR constitutive activity $[2,3,11,23,37]$. Experimentally produced animal TSHR MAbs are useful tools in studies of the TSHR.

Analysis of the solved structures of the TSHR-M22 and TSHRK1-70 complexes and of models of the TSHR-TSH complex has provided valuable insight into how the different ligands interact with the receptor. The overall binding arrangements between the TSHR and the stimulating and blocking autoantibodies and TSH itself show remarkable similarities. All the ligands interact with large areas of the concave surface of the TSHR LRD. There are, however, differences in the type of interactions; both types of autoantibodies produce a greater number of hydrogen bonds and salt bridges than TSH while there are fewer hydrophobic interactions than TSH $[24,28,32]$. There are striking similarities in the way M $22 \mathrm{HC}$ and LC mimic binding of TSH $\alpha$ and $\beta$ chains to the receptor $[24,28]$. TSH and the stimulating MAb M22 bind to the residues from all 1-10 LRR present in the structure. In contrast K1-70 does not interact with the residues in the $9^{\text {th }}$ and $10^{\text {th }}$ LRR with only one interaction in the $8^{\text {th }}$ repeat. The arrangements observed in the solved structures or the TSHR-TSH model were confirmed by studying the effect of TSHR amino acid mutations on the activity of the ligand ( $\bullet$ Table 2 and $\bullet$ Fig. 6 ). This analysis revealed that as many as 17 TSHR residues in the centre of the concave face of the LRD interact with both the stimulating MAb M22 and the blocking MAb K1-70 [28].

Analyses of the crystal structures of the TSHR LRD in complex with both M22 and K1-70 [24,32] and the model of the TSHR LRD in complex with TSH [28] showed that several patches with a similar charge (a positive patch surrounded by a circular negative patch) can be identified on the electrostatic potential surfaces of the 3 ligands (M22, K1-70 and TSH). These interact with their complementary charged patches on the concave surface of the TSHR LRD [23] and such observations were used to predict the relative positions of the binding of K1-18, RSR-B2 and 5C9 with respect to the concave surface of the TSHR LRD. The predicted positions were validated by assessing the effects of TSHR amino acid mutations on the biological activities of RSR-B2, K1-18 and 5C9 ( $\odot$ Table 2). Analyses of predictive binding of K1-18 to the TSHR [23] suggest that the antibody binds to a similar area on the TSHR LRD as the stimulating MAb M22 but is rotated by approximately $190^{\circ}$ about an axis perpendicular to the concave surface of the TSHR LRD. In this arrangement the K1-18 LC interacts with an area on the TSHR similar to the area that interacts with $\mathrm{M} 22 \mathrm{HC}$ and the $\mathrm{K} 1-18 \mathrm{HC}$ binds to a region on the TSHR that forms interactions with M22 LC. Both, M22 and $\mathrm{K} 1-18$ interact with almost the whole concave surface including the C-terminal region of the TSHR LRD. In the model of the RSRB2-TSHR complex [23], the blocking MAb RSR-B2 interacts with a similar region on the TSHR LRD as the blocking MAb K1-70 but is rotated by approximately $150^{\circ}$ about an axis perpendicular to the concave surface of the TSHR LRD. RSR-B2 does not interact with the C-terminal region of the TSHR LRD in the model and this is similar to the binding arrangements of K1-70 with the TSHR LRD seen in the crystal structure. In the model of 5C9 binding to the TSHR LRD, 5C9 is predicted to interact with all repeats of the LRD. Also 5C9 may interact with a region of the C terminus of the concave surface of the TSHR LRD, around Glu251. The antibody 5C9 has a very long CDR H3 that protrudes from its antigen binding site and this may interact with the lateral surface (surface between the concave and convex surfaces) and/or the convex surface of the TSHR LRD. This observation was supported by experiments with TSHR mutation Glu178Ala (located in the lateral surface of the LRD) that reduced the ability of 5C9 to block stimulation of the TSHR by TSH [11].

TSHR residue mutations that affect the activity of K1-18, RSR$\mathrm{B} 2,5 \mathrm{C}$, and TSH are located within areas of the receptor where the models show the ligands bind. The observed interactions in the M22-TSHR LRD and K1-70-TSHR LRD complexes (crystal 
Table 2 The agonist activity of TSH, M22 and K1-18 and TSH antagonist activity of 5C9, RSR-B2 and K1-70.

\begin{tabular}{|c|c|c|c|c|c|c|}
\hline $\begin{array}{l}\text { Leucine rich } \\
\text { repeat }\end{array}$ & $\begin{array}{l}\text { TSHR residues that } \\
\text { interact with TSH (data } \\
\text { from the TSH-TSHR LRD } \\
\text { comparative model) }\end{array}$ & $\begin{array}{l}\text { TSHR residues } \\
\text { that interact with } \\
\text { the TSHR agonist } \\
\text { M22 (data from } \\
\text { the M22-TSHR LRD } \\
\text { crystal structure) }\end{array}$ & $\begin{array}{l}\text { TSHR residues } \\
\text { important for } \\
\text { TSHR agonist } \\
\text { activity of K1- } \\
18 \text { (mutation } \\
\text { studies) }\end{array}$ & $\begin{array}{l}\text { TSHR residues } \\
\text { important for TSH } \\
\text { antagonist activity } \\
\text { of } 5 \mathrm{Cg} \text { (mutation } \\
\text { studies) }\end{array}$ & $\begin{array}{l}\text { TSHR residues that } \\
\text { interact with the TSHR } \\
\text { antagonist K1-70 } \\
\text { (data from the K1- } \\
\text { 70-TSHR LRD crystal } \\
\text { structure) }\end{array}$ & $\begin{array}{l}\text { TSHR residues } \\
\text { important for TSH } \\
\text { antagonist activity } \\
\text { of RSR-B2 (muta- } \\
\text { tion studies) }\end{array}$ \\
\hline $\mathrm{N}$-terminus & & E34 & & & & \\
\hline \multirow[t]{5}{*}{1} & & E35 & & & E35 & \\
\hline & & D36 & & & D36 & D36 \\
\hline & R38 & R38 & & & R38 & R38 \\
\hline & & & & & K42 & \\
\hline & D43* & & & & & \\
\hline \multirow[t]{5}{*}{2} & & & & & Q55 & \\
\hline & & T56 & & & & \\
\hline & K58 & K58 & & & K58* & K58 \\
\hline & & & & & $160^{*}$ & \\
\hline & $\mathrm{E} 61^{*}$ & & & & E61 & \\
\hline \multirow[t]{5}{*}{3} & R80 & R80* & & & R80 & R80 \\
\hline & & Y82* & & & Y82* & Y82 \\
\hline & & & & & S84 & \\
\hline & 185 & & & & & \\
\hline & V87 & & & & & \\
\hline \multirow[t]{7}{*}{4} & & & & & T104 & \\
\hline & $\mathrm{H} 105$ & $\mathrm{H} 105^{*}$ & & & $\mathrm{H} 105$ & \\
\hline & $\mathrm{E} 107^{*}$ & E107* & & & E107 & \\
\hline & R109 & R109* & & & R109* & R109 \\
\hline & N110 & N110 & & & N110 & \\
\hline & T111 & & & & & \\
\hline & R112 & & & & & \\
\hline \multirow[t]{5}{*}{5} & & K129* & & K129 & K129 & K129 \\
\hline & F130 & $\mathrm{F} 130^{*}$ & & & F130 & \\
\hline & F134 & & & & & F134 \\
\hline & N135 & & & & & \\
\hline & D151 & D151* & & & D151 & \\
\hline \multirow[t]{6}{*}{6} & 1152 & 1152 & & & & \\
\hline & F153 & F153* & & & F153 & \\
\hline & 1155 & 1155 & & & 1155 & \\
\hline & E157* & E157 & E157 & & E157 & \\
\hline & D160 & D160 & D160 & & & \\
\hline & P162 & & & & & \\
\hline \multirow[t]{4}{*}{7} & & & & E178 & & \\
\hline & & & & & T181 & \\
\hline & K183 & K183* & K183 & K183 & K183* & \\
\hline & Y185 & $\mathrm{Y} 185^{*}$ & Y185 & & & \\
\hline \multirow[t]{4}{*}{8} & D203* & & & D203 & D203 & \\
\hline & & & Y206 & & & \\
\hline & & N208 & & & & \\
\hline & K209 & K209* & & & & \\
\hline \multirow[t]{3}{*}{9} & S229 & & & & & \\
\hline & & & D232 & & & \\
\hline & Q235* & Q235 & & & & \\
\hline \multirow[t]{5}{*}{10} & K250 & & & & & \\
\hline & E251 & E251 & & E251 & & \\
\hline & & $\mathrm{R} 255^{*}$ & R255 & & & \\
\hline & & N256 & & & & \\
\hline & & W258* & W258 & & & \\
\hline 11 & & & R274 & & & \\
\hline
\end{tabular}




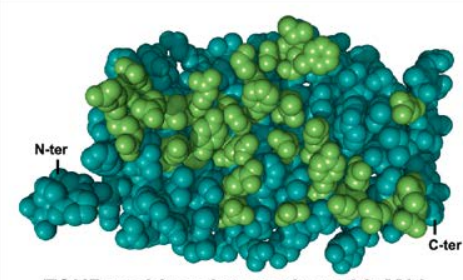

TSHR residues interacting with M22

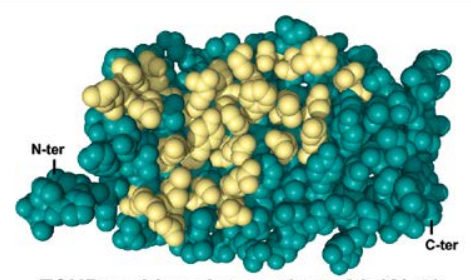

TSHR residues interacting with K1-70

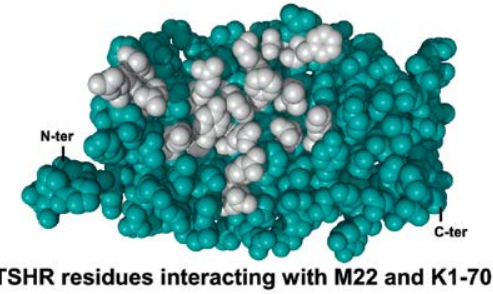

Fig. 6 The concave surface of the TSHR LRD shown in spacefill format. TSHR residues that interact with thyroid stimulating human monoclonal autoantibody $\mathrm{M} 22$ and the residues that interact with the TSHR blocking human monoclonal autoantibody $\mathrm{K} 1-70$ are indicated in green and yellow respectively. The 17 TSHR residues that interact with both $\mathrm{M} 22$ and $\mathrm{K} 1-70$ are shown in light grey. Reproduced from Figure 6 of Sanders et al. [32] (BioScientifica Ltd).

\section{Applications of TSHR MAbs in in Vitro Diagnostics $\nabla$}

TSHR MAbs are useful reagents in improved methods to detect TRAbs in test samples and as reference preparations for measurement of TRAb concentration and bioactivity.

The first generation TRAb assay developed in the early 1980s was based on the ability of TRAbs in test sera to inhibit binding of radiolabelled TSH to detergent solubilised TSHR preparations with the labelled TSH-TSHR complexes precipitated with polyethylene glycol [41]. These first generation assays are still widely used but they are technically demanding and require centrifugation and use of radioactive material. The first generation assays detect TRAbs with a sensitivity of about $2 \mathrm{IU} / \mathrm{l}$ of International Standard NIBSC 90/672 (० Fig. 7) [42]. A key improvement for the assay was dependent on the development of high affinity MAbs which could be used to immobilize detergent solubilised

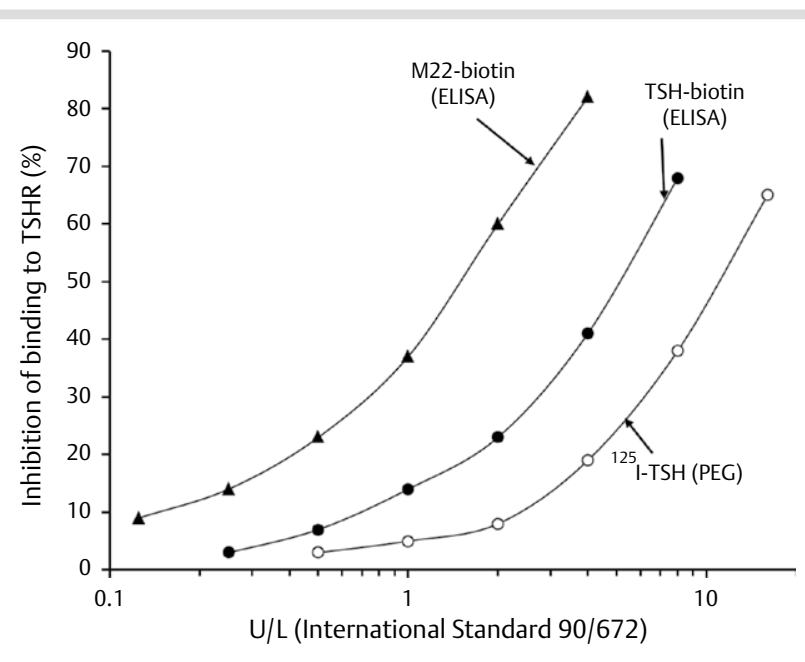

Fig. 7 The sensitivity of different generations of assays for TSHR autoantibodies. Effects of NIBSC 90/672 on inhibition of binding to the thyrotropin receptor (TSHR) in different assays for TSHR autoantibodies. M22-biotin based enzyme linked immunosorbent assay (ELISA) ( $\mathbf{\Lambda}$ ); TSH-biotin based ELISA $(\bullet)$ and ${ }^{125}$-TSH polyethylene glycol (PEG) based assay (O). PEG based assays have a sensitivity of about 2 IU/I, TSH-biotin based ELISA of about $1 \mathrm{IU} / \mathrm{I}$ and M22-biotin based ELISA of about $0.4 \mathrm{IU} / \mathrm{I}$. Reproduced from Figure 1 of Rees Smith et al. [42] (Copyright Mary Ann Liebert Inc, 2004).

TSHRs on plastic surfaces in such a way that the immobilised receptor still bound TSH and TRAb. In some of these $2^{\text {nd }}$ generation assays a monoclonal antibody to the TSHR C-terminus is employed to immobilise the receptor on the surface of a plastic tube or an ELISA plate well. Patient serum TRAb bind to the immobilised TSHR and the tubes (or plate wells) are washed prior to adding labelled TSH. In $2^{\text {nd }}$ generation assays TSH can be labelled with ${ }^{125} \mathrm{I}$, with a chemiluminescence reagent, or with biotin. In a widely used ELISA, TSH-biotin bound to the TSH receptor immobilised on ELISA plate wells is detected using streptavidin peroxidase. The ability to carry out an extensive pre-incubation of test sera with immobilised receptor and a wash step prior to addition of labelled TSH allowed improvement in sensitivity to about $1 \mathrm{IU} / \mathrm{l}$ of NIBSC 90/672 [42]. The $3^{\text {rd }}$ generation assays have a similar format to the $2^{\text {nd }}$ generation assays except that TSHR MAb M22 is used instead of TSH. The assays based on inhibition of M22 binding show improved sensi- 
tivity allowing detection of as little as $0.4 \mathrm{IU} / \mathrm{l}$ of NIBSC $90 / 672$ (॰ Fig. 7) [42].

The advantages of $3^{\text {rd }}$ generation assays are related to the special features of M22 binding to the TSHR. In particular, labelled M22 IgG does not dissociate readily once bound to the TSHR coated onto plastic surfaces even in the presence of excess, unlabelled M22 IgG. In contrast, labelled TSH dissociates from the TSHR after addition of unlabelled M22 IgG or unlabelled TSH relatively quickly [16]. The blocking human MAb K1-70 shows similar properties to M22 and therefore both types of human MAbs can be used in assays for TRAbs. These dissociation characteristics are of particular advantage in the automated TRAb assays that require the ligand to remain bound during stringent washing steps [43]. Also, the high affinity of M22 (or K1-70) for the TSHR allows very small amounts of TSHR to be used, thus improving assay sensitivity.

One of the important goals in antibody measurements is to harmonize the results obtained from different assay formats available from different manufacturers. The WHO Expert Committee on Biological Standardization established in 1995 the reference preparation coded 90/672 for the purpose of the calibration of both TRAb bioassays and receptor binding TRAb assays. The $90 / 672$ preparation was prepared from the plasma of a pregnant woman with high levels of stimulating TRAbs and the stocks of this preparation eventually ran out in 2006 . Consequently a $2^{\text {nd }}$ International Standard coded 08/204 was established to replace the $90 / 672$ preparation. NIBSC 08/204 contains freeze-dried human MAb M22 (at $1 \mu \mathrm{g}$ per vial) in normal human serum. The $2^{\text {nd }}$ International Standard 08/204 was tested in receptor binding assays and bioassays in 13 laboratories in 6 countries and compared with the $90 / 672$ standard. The potency of the $08 / 204$ standard is $0.113 \mathrm{IU}$ per ampoule based on receptor binding assays (http://www.nibsc.org/). The advantage of the 08/204 standard based on human MAb M22 is that it can easily be replaced with an identical standard if the stocks become exhausted.

TSHR MAbs also have potential applications in the detection of TSHR in tissue sections by immunohistochemistry. Biotinylated M22 or K1-70 showed strongly positive staining at the basal and lateral surfaces of thyroid epithelial cells consistent with the presence of the TSHR at these locations. The intensity of the reaction ranged from minimal specific positive staining at $0.078 \mu \mathrm{g} / \mathrm{ml}$, mild specific positive staining at $0.313 \mu \mathrm{g} / \mathrm{ml}$, moderate at $2.5 \mu \mathrm{g} / \mathrm{ml}$ and heavy at $10 \mu \mathrm{g} / \mathrm{ml}$. The stimulating MAb M22 and the blocking MAb K1-70 showed very similar reactivity to the TSHR by immunohistochemistry in agreement with the similarities in binding characteristics of these antibodies to the TSHR. There was no specific staining with a panel of human control tissues. Highly specific binding of M22 and K1-70 at low concentrations to the TSHR expressed in human thyroid tissue suggests that these MAbs when appropriately labelled are likely to be useful for in vivo imaging as well.

\section{Applications for TSHR MAbs in Vivo and Comparison with Small Molecule TSHR Agonists and Antagonists $\nabla$}

There has been a steady increase in antibody drug use in clinical practice in recent years. A large proportion of those currently on the market are mouse (or rat) antibodies or are derived from animal antibodies by molecular engineering to reduce immunogenicity and improve pharmacodynamic profiles. Molecular engineering includes creating chimeric antibodies wherein the mouse variable regions are transplanted onto a human immunoglobulin scaffold or humanised antibodies wherein only the animal CDRs are grafted onto a human immunoglobulin [44-46]. However, the most desirable in clinical practice are fully human antibodies due to their likely better pharmacokinetic/pharmacodynamic profiles and potentially low immunogenicity [44-46]. The ability of M22 and K1-70 to bind to human thyroid sections even at low concentrations as shown in immunohistochemistry studies $[3,47]$ suggests that the 2 MAbs could be used for imaging in vivo of the thyroid, thyroid cancer and thyroid cancer metastases. In addition the MAbs could be used to deliver radionuclide or chemotherapeutic drugs to tissues containing the TSHR. The blocking MAb K1-70 would be of advantage over M22 in these applications as its use would avoid any potential stimulation of thyroid cancer tissues.

However, the potent stimulating activity of M22 is potentially an advantage as an alternative to recombinant human TSH for stimulating the TSHR in in vivo diagnostic procedures in patients with thyroid cancer [48]. The potent thyroid stimulating activity of M22 has been demonstrated in vivo in experimental animals with single intramuscular injections of increasing doses of M22 $\operatorname{IgG}(2,4$ and $10 \mu \mathrm{g}$ per animal) into T3-supressed rats causing dose dependent increases in serum total and free T4 levels. The effect was detectable as soon as $4 \mathrm{~h}$ post injection of $10 \mu \mathrm{g}$ M22 with maximum $\mathrm{T} 4$ levels seen at $24 \mathrm{~h}$ post injection followed by a slow decrease up to $120 \mathrm{~h}$ [47]. Thyroid sections from the dosed animals showed evidence of thyroid cell hypertrophy consistent with the stimulating effect of M22 [47]. Although in vivo effects of M22 on radioiodine uptake have not been studied as yet low doses of M22 would be expected to act as a powerful, fast and long acting thyroid stimulator in humans. This may provide improvements in the management of thyroid cancer whereby only one injection of M22 would be sufficient for adequate stimulation of TSHR expressing tissues instead of 2 injections of recombinant human TSH on consecutive days as in current protocols [48]. However, the relatively slow dissociation rate of M22 from the TSHR compared to TSH needs to be considered [16]. Furthermore, M22 may be useful in strategies for improving the effectiveness of ${ }^{131}$ I therapy in patients with thyroid nodular disease [49-51].

Current therapeutic options for Graves' disease are targeted at the ability of thyroid cells to produce thyroid hormones and include prolonged treatment (over several months or longer) with antithyroid drugs, total thyroidectomy or destruction of the thyroid gland with radioactive iodine [52-55]. TRAbs with TSHR blocking activities are "natural" inhibitors of TSHR stimulation by both stimulating TRAbs and TSH and could be used to control thyroid overactivity in Graves' disease and in other patients who would benefit from blocking TSHR stimulation.

A single intramuscular injection of $200 \mu \mathrm{g}$ of $\mathrm{K} 1-70$ into rats caused a decrease of serum total and free T4 levels to those observed in T3 supressed animals. This complete decrease in serum T4 levels was evident at $24 \mathrm{~h}$ post injection [47]. Further, the ability of K1-70 to inhibit the effect of thyroid stimulation by M22 in vivo could be shown. In these experiments rats were

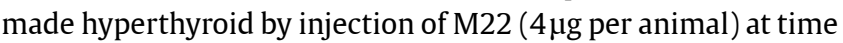
$0 \mathrm{~h}$ followed by injection of K1-70 at different doses at $24 \mathrm{~h}$ (๑ Fig. 8a). K1-70 caused a decrease of serum T4 levels stimulated by M22 in a dose dependent manner with a $100 \mu \mathrm{g}$ and $200 \mu \mathrm{g}$ dose per animal being the most effective. A single dose of $100 \mu \mathrm{g}$ of K1-70 IgG per animal was tested for its effectiveness at 
decreasing the elevated serum T4 levels stimulated by different doses of M22 (4, 10, 20 and $40 \mu \mathrm{g}$ per animal) (O Fig. 8b, c). $\mathrm{K} 1-70 \mathrm{IgG}$ at a single dose of $100 \mu \mathrm{g}$ was effective at inhibiting thyroid stimulating activity of M22 at all doses studied in vivo with rapid (within $12 \mathrm{~h}$ ) decrease in serum T4 levels. The decrease in serum T4 levels was complete, that is, to the levels observed in T3 supressed animals.

Measured TRAb concentrations in Graves' sera usually range from 50 to $500 \mathrm{ng} / \mathrm{ml}$ although in exceptional patients they may reach $3000 \mathrm{ng} / \mathrm{ml}$ [16]. M22 rat serum concentrations $24 \mathrm{~h}$ after

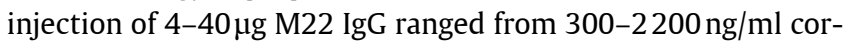
responding well with the TRAb levels observed in Graves' patients. In in vivo experiments, a single $100 \mu \mathrm{g}$ dose of K1-70 IgG was effective in blocking the biological effect of the same M22 concentrations as those observed for TRAbs in Graves' sera. It would be expected that a single dose of approximately $10 \mathrm{mg}$ of K1-70 IgG would be sufficient to counteract the effects of TSHR stimulating autoantibodies in the majority of patients with Graves' disease.

The effects of "natural" thyroid stimulating or blocking MAbs can be compared with the effects of small molecule TSHR agonists and antagonists. The small molecule TSHR agonists and antagonists are designed to act on the TSHR transmembrane domain (TMD) as the TSHR ECD is not a suitable target due to the extensive hormone-receptor interface (see above). The small molecule TSHR candidate drugs act via an allosteric modulation mechanism, that is, cause changes in conformation of the receptor's transmembrane helices, and/or extracellular loops. It is proposed that one of the interactions involved in activation of GPCRs is dependent on polar interactions between the TMD helices forming an "ionic lock" [56,57]. An antagonist would stabilize the "ionic lock" and prevent signalling while an agonist would destabilise the "ionic lock" and allow for the signal transduction. Due to a high level of sequence and structural homology among the GPCRs small molecules acting in this way may show unexpected cross-reactivities with other receptors or enzymes. However, recent phase 1 clinical trials with small molecule LHR agonists have not highlighted specificity concerns albeit these drug candidates were used for a short time and had short elimination half-lives (up to $47 \mathrm{~h}$ ) [58].

Small molecules which target the TSHR do not appear to have progressed from early development to clinical trials due to unwanted effects on the FSHR and the LHR at the concentrations needed to be effective for the TSHR [59]. Further developments have produced full agonists with a potency expressed as Ec50 value in the range of $660 \mathrm{nmol} / 1$ (Compound 1) or $40 \mathrm{nmol} / 1$ (Compound 2) and with no detectable reactivity with the FSHR or LHR being reported [60]. Doses of $0.5 \mathrm{mg}$ administered intraperitoneally or $2.5 \mathrm{mg}$ orally of Compound 2 were reported to increase serum T4 levels in experimental animals [60]. In contrast, microgram doses and serum concentrations of only 1-2 $\mathrm{nmol} / \mathrm{l}$ of the stimulating MAb M22 effectively increased T4 levels in rats [47].

The small molecule TSHR antagonist (ANTAG3) described recently showed an ability to lower serum T4 levels in mice [61] with a half-maximal inhibiting effect on the TSHR in vitro at approximately $2 \mu \mathrm{mol} / 1$ concentrations. ANTAG3 also inhibited LHR and FSHR activities at higher concentrations (approximately $30 \mu \mathrm{mol} / \mathrm{l}$ ). In these experiments, ANTAG3 was administered to mice by continuous intraperitoneal infusion for 3 days at $2 \mathrm{mg} /$ day together with TRH at $2.4 \mu \mathrm{g} / \mathrm{day}$. Also the effect of ANTAG3 (at $2 \mathrm{mg} /$ day infusion for 3 days plus additional $2 \mathrm{mg}$ injection)
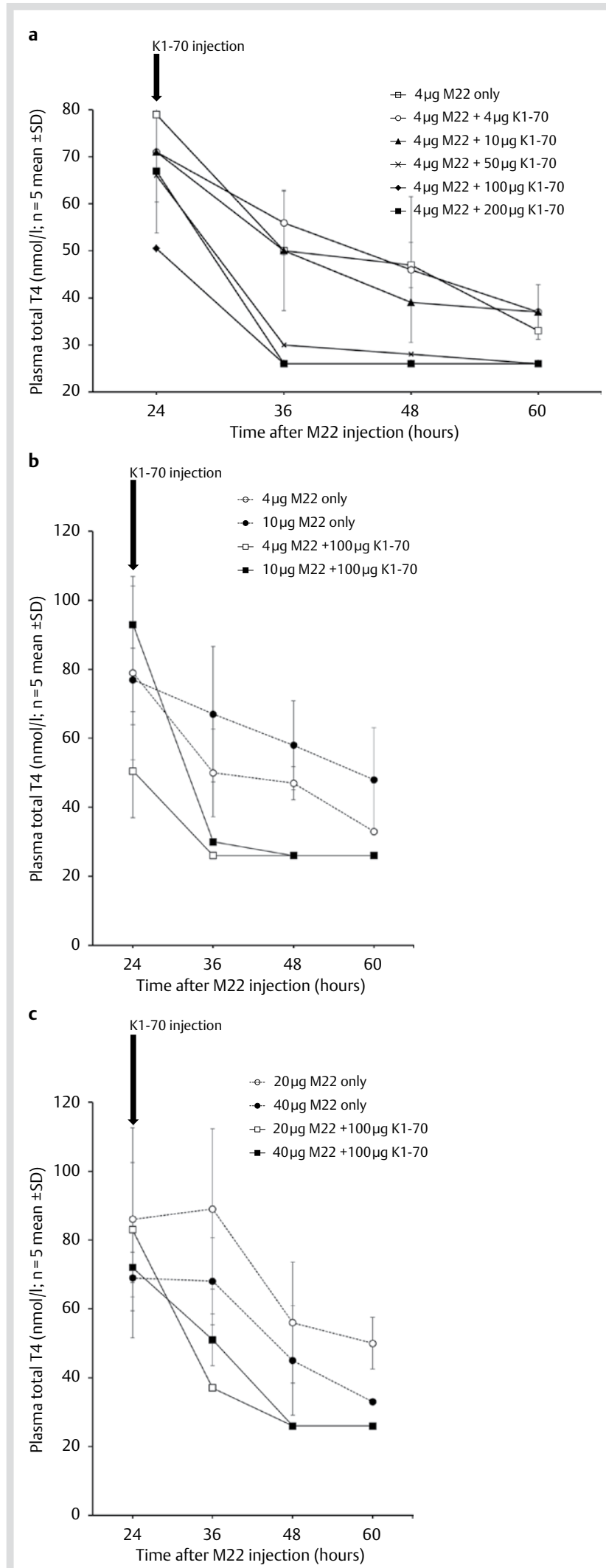

Fig. 8 Effect of TSHR blocking human monoclonal autoantibody K1-70 on elevated T4 levels stimulated by administration of human monoclonal autoantibody M22 in vivo in rats. a The effect of different doses of K1-70 on $\mathrm{T} 44$ levels stimulated by a single dose of M22 ( $4 \mu \mathrm{g}$ per animal). $\mathbf{b}$ The effect of K1-70 (100 $\mu$ g per animal) on elevated T4 levels stimulated by different doses of M22 $(4 \mu \mathrm{g}$ and $10 \mu \mathrm{g}$ per animal). c The effect of K1-70 (100 $\mu \mathrm{g}$ per animal) on elevated T4 levels stimulated by different doses of M22 (20 $\mu \mathrm{g}$ and $40 \mu \mathrm{g}$ per animal). Reproduced with permission of the copyright holder, RSR Ltd. 
Table 3 Control of TSHR activity by small molecules and by monoclonal antibodies. Preparations with TSHR agonist activity.

\begin{tabular}{|c|c|c|c|c|}
\hline \multicolumn{5}{|c|}{ Small molecule agonists } \\
\hline \multirow[t]{2}{*}{ Compound } & \multirow[t]{2}{*}{ Target } & \multirow[t]{2}{*}{ Potency for TSHR } & \multicolumn{2}{|c|}{ Specificity } \\
\hline & & & FSHR & LHR \\
\hline Org 41841 [82] & $\begin{array}{l}\text { TSHR transmembrane } \\
\text { domain }\end{array}$ & Partial agonist Ec50 $7700 \mathrm{nM}$ & not available & $\begin{array}{l}\text { Partial agonist } \\
\text { Ec50 220 nM }\end{array}$ \\
\hline $\begin{array}{l}\text { Compound } 1 \text { [60] } \\
\text { (NCGC 00168126-01) }\end{array}$ & $\begin{array}{l}\text { TSHR transmembrane } \\
\text { domain }\end{array}$ & Full agonist Ec50 660 nM & not detectable & not detectable \\
\hline $\begin{array}{l}\text { Compound } 2 \text { [60] } \\
\text { (NCGC 00161870-01) }\end{array}$ & $\begin{array}{l}\text { TSHR transmembrane } \\
\text { domain }\end{array}$ & $\begin{array}{l}\text { Full agonist Ec50 } 40 \mathrm{nM} \\
\text { In vivo (mice) } 0.5 \mathrm{mg} \text { (ip) or } 2.5 \mathrm{mg} \\
\text { (oral) doses increase serum T4 } \\
\text { In vivo (mice) increase }{ }^{125} \mathrm{I} \text { uptake after } \\
\text { oral administration }\end{array}$ & $\begin{array}{l}\text { not detectable (data not } \\
\text { shown) }\end{array}$ & $\begin{array}{l}\text { not detectable (data not } \\
\text { shown) }\end{array}$ \\
\hline MS437 [83] & $\begin{array}{l}\text { TSHR transmembrane } \\
\text { domain }\end{array}$ & $\begin{array}{l}\text { Partial agonist Ec50 } 130 \mathrm{nM} \\
\text { In vivo (mice) } 100 \mu \mathrm{g} / \text { day (ip) for } 3 \text { days } \\
\text { increase serum T4 levels }\end{array}$ & $\begin{array}{l}\text { not detectable at concen- } \\
\text { trations up to } 10 \mu \mathrm{M}\end{array}$ & $\begin{array}{l}\text { not detectable at concentra- } \\
\text { tions up to } 10 \mu \mathrm{M}\end{array}$ \\
\hline MS438 [83] & $\begin{array}{l}\text { TSHR transmembrane } \\
\text { domain }\end{array}$ & $\begin{array}{l}\text { Partial agonist Ec50 } 53 \mathrm{nM} \\
\text { In vivo (mice) } 100 \mu \mathrm{g} / \text { day (ip) for } 3 \text { days } \\
\text { increase serum T4 levels }\end{array}$ & $\begin{array}{l}\text { not detectable at concen- } \\
\text { trations up to } 10 \mu \mathrm{M}\end{array}$ & $\begin{array}{l}\text { not detectable at concentra- } \\
\text { tions up to } 10 \mu \mathrm{M}\end{array}$ \\
\hline \multicolumn{5}{|c|}{ Stimulating human MAbs } \\
\hline $\begin{array}{l}\text { M22, K1-18 } \\
{[10,21,47]}\end{array}$ & $\begin{array}{l}\text { TSHR extracellular } \\
\text { domain }\end{array}$ & $\begin{array}{l}\text { Full agonist at } 700 \mathrm{pM} \text { (both } \mathrm{M} 22 \text { and } \\
\mathrm{K} 1-18 \text { ) } \\
\text { In vivo (rats) single } \mathrm{M} 222-10 \mu \mathrm{g} \text { doses } \\
\text { (im) increase serum } \mathrm{T} 4 \text {; effective at } \\
0.4-1.8 \mathrm{nM} \text { serum concentrations }\end{array}$ & $\begin{array}{l}\text { No detectable reactivity } \\
\text { at } 70 \mathrm{nM} \text {, i.e., } 100 \times \text { molar } \\
\text { concentration of FSH } \\
\text { causing stimulation (both } \\
\text { M22 and } \mathrm{K} 1-18 \text { ) }\end{array}$ & $\begin{array}{l}\text { No detectable reactivity at } \\
70 \text { nM for M22, i. e., } \\
20000 \times \text { molar concentration } \\
\text { of hCG causing stimulation. } \\
\text { No detectable reactivity at } \\
35 \text { nM for K1-18, i.e., } \\
10000 \times \text { molar concentration } \\
\text { of hCG causing stimulation }\end{array}$ \\
\hline
\end{tabular}

on thyroid stimulation by M22 in vivo was studied. ANTAG3 lowered TRH stimulated free T4 levels by $44 \%$ and lowered M22 stimulated free T4 levels by $38 \%$ [61]. The reported in vivo potency of ANTAG3 and the relatively high concentrations needed for an effect suggest limited suitability of this antagonist for clinical applications [57]. In contrast, a single $100 \mu \mathrm{g}$ dose of K1-70 injected intramuscularly into rats caused rapid decrease in T4 levels to those seen in T3 supressed animals. This complete decrease of T4 levels corresponded to rat serum K1-70 concentrations of only $40 \mathrm{nmol} / \mathrm{l}$ [47].

Neither M22 nor K1-70 had an effect on FSHR or LHR activity in vitro when tested at 15-30 times higher molar concentrations than were effective on the TSHR in the in vivo experiments.

There are key differences between the small molecule TSHR agonists/antagonists and our TSHR MAb drug candidates ( Table 3,4). Although some small molecule TSHR agonists and antagonists, (described to date) are effective or partially effective at $\mathrm{nmol} / \mathrm{l}$ concentrations in vitro some are potent only at higher concentrations. Furthermore, they have detectable crossreactivity with the FSHR and LHR or may have cross-reactivity with as yet untested receptors or enzymes especially at the high doses needed to be effective in vivo [57]. In contrast, "natural" TSHR agonist (M22) and antagonist (K1-70) are completely (100\%) effective in vivo at single $\mu \mathrm{g}$ doses and nmol/l serum concentrations and are highly specific for the TSHR. Furthermore, in patients with Graves' disease or patients with blocking type TSHR autoantibodies, there is no evidence of an effect of TSHR autoantibodies on other receptor/enzyme systems. The high TSHR specificity and the potent in vivo activity of M22 and K1-70 suggests that these MAbs have considerable potential in clinical applications and the clinical potential for M22 has been discussed above. Important potential clinical applications of K1-70 are in controlling Graves' disease including challenging clinical situations such as thyroid crisis when effective and fast acting interventions to decrease serum levels of thyroid hormones are essential [54,62]. Also K1-70 would potentially be of considerable benefit in patients who are intolerant of antithyroid drugs. Furthermore, in patients with toxic nodular goitre K1-70 would help to reduce thyroid hormone levels before radioiodine treatment takes effect. In pregnant women with Graves' thyrotoxicosis, treatment with K1-70 Fab would control the symptoms in the mother without affecting the foetal thyroid as antibody Fab fragments do not cross the placenta unlike the intact IgGs. Another potential application for K1-70 is in controlling hyperthyroidism caused by autonomous secretion of TSH by pituitary adenomas.

The management of Graves' ophthalmopathy remains a great challenge. Recent evidence from several studies strongly supports the involvement of the TSHR in the pathogenesis of Graves' orbitopathy [63-65]. Furthermore, it has been demonstrated that M22 has the ability to activate TSHRs expressed in orbital tissues via standard activating pathways including the phosphoinositide 3-kinase pathway [66]. Consequently, K1-70 would be expected to have a blocking effect on the activity of the TSHR in orbital fibroblasts/adipocytes. Current treatment strategies in patients with Graves' ophthalmopathy include use of glucocorticoids, orbital irradiation and surgical decompression and in many cases are unsatisfactory $[67,68]$. Of the new approaches, Rituximab acting on B-lymphocytes has shown some promising results in clinical trials $[69,70]$. However the ability of K1-70 to block the activity of the TSHR specifically and at low doses suggests it would be of considerable benefit in controlling the development and progression of Graves' eye disease. Furthermore, it should do so without the side effects of nonspecific therapies such as steroids and/or Rituximab. 
Table 4 Control of TSHR activity by small molecules and by monoclonal antibodies. Preparations with TSHR antagonist activity.

\begin{tabular}{|c|c|c|c|c|}
\hline \multicolumn{5}{|c|}{ Small molecule antagonists } \\
\hline \multirow[t]{2}{*}{ Compound } & \multirow[t]{2}{*}{ Target } & \multirow[t]{2}{*}{ Potency for TSHR } & \multicolumn{2}{|c|}{ Specificity } \\
\hline & & & FSHR & LHR \\
\hline $\begin{array}{l}\text { Compound } 52 \\
\text { (NIDDK/CEB-52) } \\
{[84]}\end{array}$ & $\begin{array}{l}\text { TSHR transmem- } \\
\text { brane domain }\end{array}$ & $\begin{array}{l}\text { Ic50 for TSH } 4200 \mathrm{nM} \\
71 \% \text { inhibition of TSH mediated cyclic AMP stimulation at } \\
30 \mu \mathrm{M} \\
28-79 \% \text { inhibition of TSHR autoantibody stimulation of } \\
\text { cyclic AMP production at } 30 \mu \mathrm{M}\end{array}$ & $\begin{array}{l}\text { No detectable reactivity } \\
\text { (data not shown) }\end{array}$ & $\begin{array}{l}\text { Partial agonist }(17 \% \\
\text { compared to } 100 \% \\
\text { for } L H)\end{array}$ \\
\hline $\begin{array}{l}\text { Org 274179-0 } \\
{[59]}\end{array}$ & $\begin{array}{l}\text { TSHR transmem- } \\
\text { brane domain }\end{array}$ & $\begin{array}{l}\text { Full antagonist activity with Ic50 for TSH } 9 \mathrm{nM} \\
\text { Complete inhibition of TSH, M } 22 \text { and TSHR autoantibody } \\
\text { stimulation of cyclic AMP production at 5-11 nM } \\
\text { Inhibits basal activity with Ic } 5022 \mathrm{nM} \text {. }\end{array}$ & $\begin{array}{l}\text { Full antagonist activity } \\
\text { with Ic50 for FSH } \\
17 \mathrm{nM}\end{array}$ & $\begin{array}{l}\text { Weak antagonist } \\
\text { activity for LH with } \\
24 \pm 8 \% \text { inhibition at } \\
10 \mu \mathrm{M} \\
\text { Partial agonist activity } \\
\text { with Ec50 } 1100 \mathrm{nM}\end{array}$ \\
\hline ANTAG3 [61] & $\begin{array}{l}\text { TSHR transmem- } \\
\text { brane domain }\end{array}$ & $\begin{array}{l}\text { Ic50 for TSH antagonist activity } 2100 \mathrm{nM} \\
\text { Inhibits basal activity with Ic50 } 6000 \mathrm{nM} \text {. } \\
\text { In vivo (mice) } 2 \mathrm{mg} / \text { day (ip) for } 3 \text { days lowered TRH stimu- } \\
\text { lated T4 by } 44 \% \text { and M } 22 \text { stimulated T4 by } 38 \%\end{array}$ & $\begin{array}{l}30 \% \text { inhibition } \\
\text { compared to } 100 \% \text { for } \\
\text { FSH at } 30 \mu \mathrm{M}\end{array}$ & $\begin{array}{l}15 \% \text { inhibition } \\
\text { compared to } 100 \% \\
\text { for LH at } 30 \mu \mathrm{M}\end{array}$ \\
\hline \multicolumn{5}{|c|}{ Blocking type human MAbs } \\
\hline $\begin{array}{l}\mathrm{K} 1-70[7,8,47 \\
5 \mathrm{C} 9[11]\end{array}$ & $\begin{array}{l}\text { TSHR extracellular } \\
\text { domain }\end{array}$ & $\begin{array}{l}\text { Full TSH antagonist activity for K1-70 and for } 5 \text { C9 at } 700 \\
\text { pM (Ic50 } 250 \text { pM) } \\
\text { K1-70 does not inhibit basal activity. } \\
5 \mathrm{C} 9 \text { at } 1 \mu \mathrm{g} / \mathrm{ml}(7 \mathrm{nM} \text { ) inhibits basal cyclic AMP levels ( } 71 \% \text { ). } \\
\text { In vivo (rats) a single } \mathrm{K} 1-70100 \mu \mathrm{g} \text { dose (im) causes rapid } \\
\text { decrease of serum T4 to T3 suppressed levels; effective at } \\
40 \mathrm{nmol} / \mathrm{I} \text { serum concentrations }\end{array}$ & $\begin{array}{l}\text { K1-70 and 5C9: no } \\
\text { effect on FSH stimu- } \\
\text { lated cyclic AMP levels } \\
\text { at concentrations up to } \\
100 \mu \mathrm{g} / \mathrm{ml}(700 \mathrm{nM})\end{array}$ & $\begin{array}{l}\text { K1-70 and 5C9: no ef- } \\
\text { fect on LH stimulated } \\
\text { cyclic AMP levels at } \\
\text { concentrations up to } \\
100 \mu \mathrm{g} / \mathrm{ml}(700 \mathrm{nM})\end{array}$ \\
\hline
\end{tabular}

\section{Glycosylation Pattern Analysis of Glycoprotein Hormones and Their Receptors \\ $\nabla$}

Glycoprotein hormones (GPHs) and glycoprotein hormone receptors (GPHRs) in different species are glycosylated although the number of the attached glycans and sugar residues vary between different hormones, different receptors and among species. We have analysed the glycosylation site candidates in the amino acid sequences of GPHs and GPHRs from different species. In all, 62 amino acid sequences of glycoprotein hormone $\alpha$ subunits, 68 of FSH $\beta$ subunits, 85 of LH $\beta$ subunits, 9 of CG $\beta$ subunits and 40 of TSH $\beta$ subunits were studied. Also 34 amino acid sequences of FSH receptor ectodomains (ECDs), 24 of CG/LHR ECDs and 19 of TSH receptor ECDs were studied. From the analysis we were able to identify glycosylation site candidates on the hormones corresponding to $\mathrm{n}=15$ equivalent positions in the amino acid alignments and glycosylation site candidates on the receptors corresponding to $n=28$ equivalent positions in the alignments [71].

In addition, the study showed that some amino acid sequences of the FSHR of fishes lack the first and third Cys of their N terminus, the second Cys is conserved in all sequences studied while the fourth Cys is absent in one fish [71]. A disulphide connection of the fourth Cys (Cys41) of the TSHR with any of the other 3 cysteines appears to be crucial for TSHR trafficking to the cell surface and maintaining high affinity binding for TSH, while a second disulphide bond may not be essential [72]. Also, it has been reported that a full response of the TSHR to stimulation by TSHR autoantibodies requires Cys41 to be disulphide bonded with Cys29 or Cys31, but not with Cys24 [72]. We observed that the FSHR sequences of fishes are shorter than in tetrapods and some of the fishes also lack the tyrosine that in the human sequence (Tyr385) is sulphated [71]. Furthermore, the amino acid sequences of the LHR of 2 birds and 7 fishes have longer hairpin loops than the human sequence whereas the common marmoset (primate) has only an 8 residues long hairpin loop and lacks the 2 cysteines flanking the loop. The 2 cysteines in the long hairpin loop are probably disulphide bonded in order to avoid disruption of the structure of the hinge region. However a disulphide bond is probably not needed for this purpose in an 8 residues long loop [71]; explaining the absence of flanking cysteines in the marmoset sequence.

Glycosylation site candidates were mapped on a molecular surface representation of a model of the structure of the TSH-TSHR ECD complex (see below). Two areas on the surface of TSH and 4 areas on the surface of the TSHR that are free from glycosylation and that are not involved in currently known interactions observed in crystal structures or reliable comparative models were identified. The first area on the hormone free from glycosylation corresponds to the loop $\beta \mathrm{L} 3$ and part of the beta 3 strand and beta 4 strand of the $\beta$ subunit, and the second area corresponds to the loop $\alpha \mathrm{L} 1$ and part of the beta 1 strand and beta 2 strand of the $\alpha$ subunit [71]. Experimental evidence such as single point and deletion/mutation studies, in vitro analyses of pathogenic germline mutations and crystal structure analyses suggest that the equivalent non-glycosylated areas on the hormones and the receptors are likely to be involved in various interactions. Consequently, these non-glycosylated areas are candidates for additional (currently unknown) contacts between the receptors and their cognate hormones.

\section{Modelling of the TSHR ECD and the CG/LHR ECD \\ $\nabla$}

The structural detail available from the crystal structure of FSH in complex with the entire FSHR ECD (aa 18-359) [73] has allowed us to build comparative models of: the entire TSHR ECD (aa 24-411); the TSHR ECD in complex with TSH; the LHR ECD in complex with LH and CG; and the TSHR ECD in complex with TSHR monoclonal autoantibodies. These models permit the 

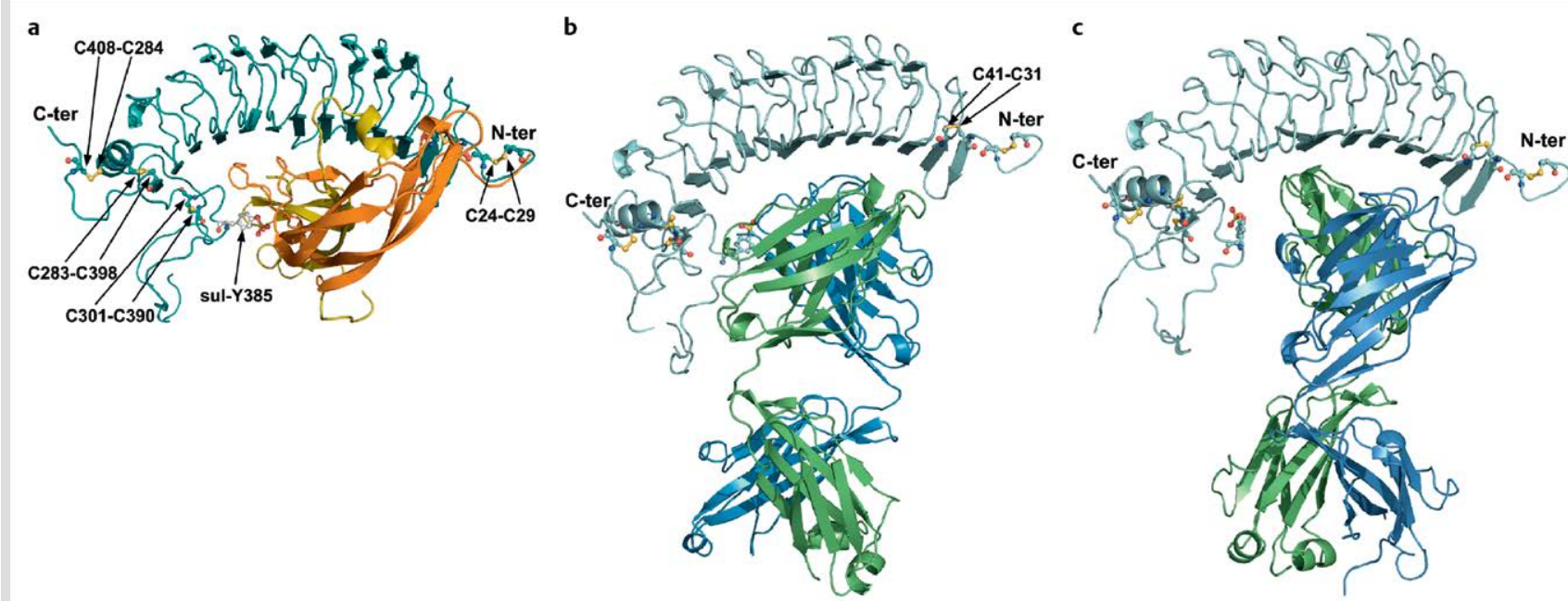

Fig. 9 Comparative models. a The TSH-TSHR ECD complex (conformational arrangements show a final stage in the proposed activation mechanism when sulphated Tyr 385 is bound to the hormone; see $\oslash$ Fig. 10d). b The M22-TSHR ECD complex. c The K1-70-TSHR ECD complex. The TSHR ECD is shown in cyan, the hormone $\alpha$ subunit is shown in olive and $\beta$ subunit in orange. Antibody light chains are shown in green and heavy chains in blue. The $\mathrm{N}$ - and $\mathrm{C}$-termini of the TSHR ECD, disulphide bonded cysteines and the TSHR sulphated Tyr385 are marked. Reproduced with permission of the copyright holder, RSR Ltd.

study of interactions beyond the LRD and possible ligand induced activation mechanisms [74].

Initial models of the structures of the TSH-TSHR ECD, the LHLHR ECD and the CG-LHR ECD complexes were predicted by comparative modelling based on the crystal structure of the FSH-FSHR ECD complex [73]. Then, the atomic coordinates of TSHR residues 24-255 from the initial model of the TSH-TSHR ECD were replaced by the atomic coordinates of the same residues from the crystal structure of the TSHR LRD from the K1-70TSHR LRD complex [32], after coordinate superimposition. The comparative model of the structure of the TSHR ECD is composed of a crystal structure of TSHR residues 24-255 and a comparative model of TSHR residues 256-411. The structure of the TSH-TSHR ECD complex is highly similar to that of the FSH-FSHR ECD complex ( $\odot$ Fig. 9a). Differences are observed in the disulphide connections at the $\mathrm{N}$ termini and the sulphated tyrosines in the amino acid sequence alignment are not equivalent. Tyr335 is sulphated in the FSHR and Tyr385 is sulphated in the TSHR which is equivalent to FSHR Phe333. The structures of the LHLHR ECD and the CG-LHR ECD complexes were not modified further due to unavailability of crystal structures of the complexes but both are highly similar to that of the FSH-FSHR ECD complex. The disulphide connection at the N-terminus of the LHR is probably similar to that of the FSHR based on the amino acid sequence alignment, whereas the sulphated tyrosine of the LHR is equivalent to that of the TSHR.

The structure of the TSHR ECD shows in addition to the 10 LRRs observed in the crystal structures of the LRD [24,32], 2 additional repeats, an $\alpha$ helix at the convex segment of repeat 11 and a long and unstructured hinge loop (H-loop) that include the approximately 50 residues segment that is cleaved out during TSHR processing.

\section{Modelling of the Complexes of M22-TSHR ECD and K1-70-TSHR ECD \\ $\nabla$}

For modelling of the structures of the TSHR in complex with TSHR autoantibodies [74], superimposition of coordinates of the
TSH-TSHR ECD model with both the M22-TSHR LRD [24] and the K1-70-TSHR LRD [32] crystal structures were performed initially. In the case of the thyroid stimulating antibody M22, the atomic coordinates of the TSHR residues 30-255 and TSH, from the model of the TSH-TSHR ECD, were replaced by the atomic coordinates of the equivalent TSHR residues and M22, respectively, from the crystal structure of the M22-TSHR LRD complex ( $\odot$ Fig. 9b). In the case of the blocking antibody K1-70, the atomic coordinates of TSH, from the model of the TSH-TSHR ECD, were replaced by the atomic coordinates of K1-70 from the crystal structure of the K1-70-TSHR LRD complex ( $\bullet$ Fig. 9c).

The models show that stimulating antibody M22 binds to the whole concave surface of the TSHR LRD and contacts LRR 1 to 12 , the hairpin loop of the hinge region and the $C$ terminus of the TSHR ECD. The blocking antibody K1-70 binds to part of the concave surface of the TSHR LRD and contacts LRR 1-8 while it does not contact the hinge region or the $\mathrm{C}$ terminus.

\section{Proposed Mechanism of TSHR Activation by TSH and M22 \\ $\nabla$}

The models of the structures of the TSH-TSHR ECD and LH-LHR ECD complexes based on the FSH-FSHR ECD crystal structure predict that the activation mechanisms of the 3 glycoprotein hormone receptors by their cognate hormones are likely to be similar. The crystal structure of the FSH-FSHR ECD complex [73] is in the active state, as the hormone is bound. Therefore, the models of the structures of the TSH-TSHR ECD and LH-LHR ECD represent their active states. The first step in a proposed activation mechanism is the hormone contacting LRR 1-10 of the receptor LRD followed by conformational modifications of the hormone in the $\beta$ L2 loop, that opens the hormone sulphatedtyrosine binding pocket ( $\odot$ Fig. 10a, b). Then, the receptor's negatively charged sulphate on Tyr385 is attracted by the positively charged sulphated-tyrosine binding pocket on the hormone causing the receptor's hinge loop to move towards the hormone $(\odot$ Fig. 10c, d). This hinge loop movement may modify the positions of the convex segments of LRRs 10 and 11 relative to each 

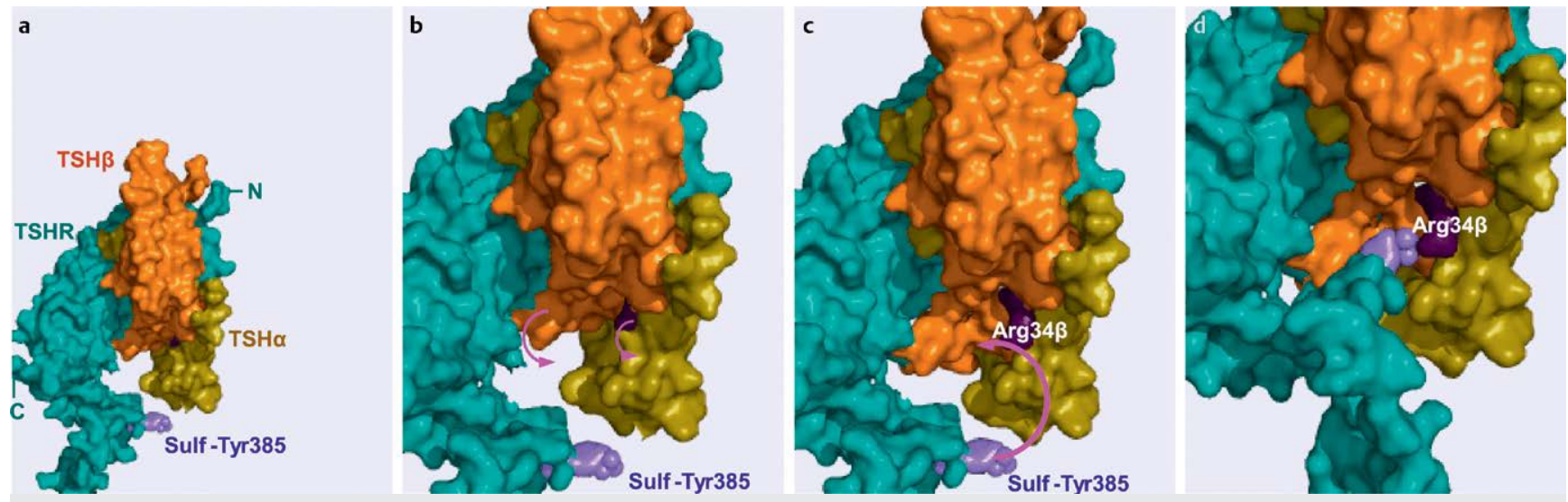

Fig. 10 Proposed activation mechanism of the TSHR by TSH. The TSHR ECD is shown in cyan, TSH $\alpha$ is shown in olive and TSH $\beta$ in orange. The N-and C-termini of the TSHR ECD and the TSHR sulphated Tyr385 are marked. The first step in receptor activation is the binding of the hormone to the concave surface of the leucine rich repeat domain of the receptor $\mathbf{a}$. The hormone undergoes conformational modifications of the $\beta L 2$ loop that open the hormone sulphated tyrosine binding pocket centred at Arg $34 \beta$ b. Then, the receptor hinge loop, with its negatively charged sulphated tyrosine moves towards the hormone attracted by the positively charged sulphated-tyrosine binding pocket on the hormone (c and $\mathbf{d})$. Reproduced with permission of the copyright holder, RSR Ltd.

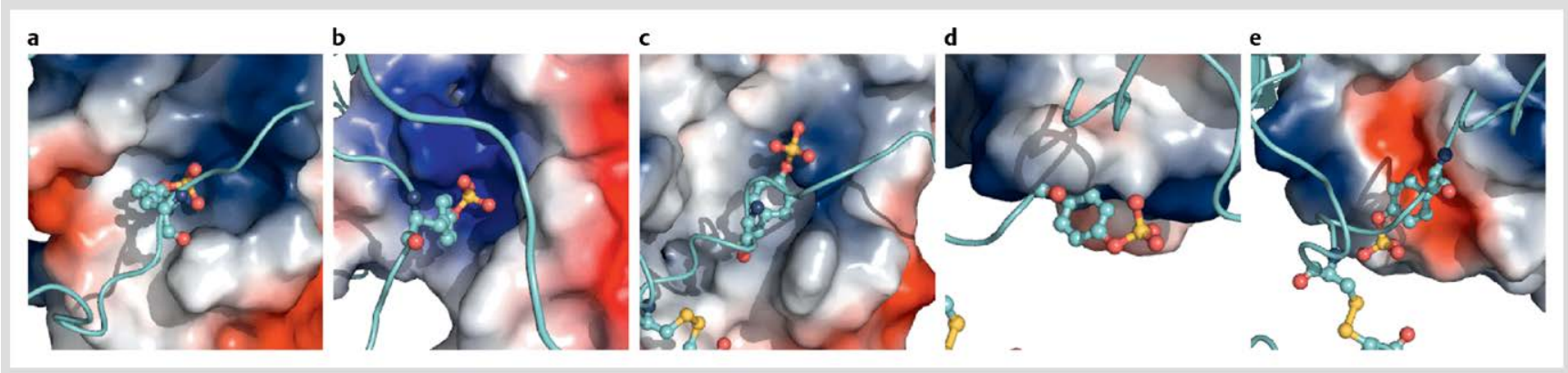

Fig. 11 Details of electrostatic potentials on the surfaces of: a FSH; b LH; c TSH; d M22; e K1-70 in the area of likely contact with their respective receptor's sulphated tyrosine (negatively charged). Negatively charged surface patches are coloured red and positively charged patches are coloured blue. The sulphated tyrosines are shown as ball-and-stick representations with carbon atoms in cyan, oxygen atoms in red and sulphur atoms in yellow. The surfaces of FSH, LH, and TSH that make contact with a sulphated tyrosine are positively charged. The surface of M22 which could potentially be in contact with the sulphated tyrosine is not charged. The equivalent surface of K1-70 is negatively charged. Reproduced with permission of the copyright holder, RSR Ltd.

other. We propose that the convex segments of LRRs 10 and 11 may be in contact with the extracellular loops of the TMD. Consequently, the change in position of LRRs 10 and 11 caused by the hinge loop movement may affect the conformations of the extracellular loops of the TMD and transmit the activation signal to the TMD $[74,75]$. TSHR Ser281, which has been implicated in receptor activation [76], is at the edge of the convex segment of repeat 11 consistent with a role in the activation process.

The models described here suggest that activation of the TSHR by TSH, the FSHR by FSH and the LHR by LH are likely to proceed by similar mechanisms [73-75]. However, it has been proposed [77] that activation of the LHR by CG proceeds by a slightly different mechanism than activation by LH. Coexpression of signalling-deficient LHR and binding-deficient LHR was used to examine the mechanisms of receptor activation by CG and LH. CG signalling was partially restored (transactivation), whereas LH signal could not be restored (no transactivation) [77]. In a different study, Jaesche et al. [78] produced TSHR chimeras by substituting the TSHR hinge region with the hinge regions of FSHR or the LHR and concluded that the hinge region of the GPHRs are exchangeable for human TSH signalling however the superagonistic activity of bovine TSH is dependent on the hinge region of the TSHR. In addition, Schaarschmidt et al. [79] have highlighted the importance of the hinge region of the GPHRs, sulphated tyrosine and signalling relevant serine (TSHR S281, FSHR S273, LHR S277) for ligand specific binding and activation.

It has been observed experimentally that sulphation of TSHR Tyr385 does not affect receptor activation by the stimulating autoantibody M22. The model of the structure of the M22TSHR ECD complex does not predict interaction between the sulphated Tyr385 and M22. The surface of M22, which could potentially be in contact with the negatively charged sulphated-Tyr385, is not charged, whereas the surfaces of FSH, LH and TSH that contact the sulphated-Tyr, are positively charged ( $\odot$ Fig. 11a-d) [74]. In the case of the TSHR blocking autoantibody K1-70 the equivalent surface is negatively charged, thus the sulphated Tyr is repelled by the antibody ( $\bullet$ Fig. 11e). In addition $\mathrm{K1-70}$ is positioned too far away from the hairpin loop to make contact.

The models of the structures of the TSH-TSHR ECD and M22TSHR ECD complexes support the concept that the mechanisms of TSHR activation by TSH and TSHR stimulating antibodies are different. 


\section{Conflict of Interest}

$\nabla$

All authors are employees of RSR Ltd. RSR Ltd is a developer of medical diagnostics including kits for measuring TSH receptor autoantibodies. The work was funded by RSR Ltd.

\section{References}

1 Rees Smith B, Sanders J, Furmaniak J. TSH receptor antibodies. Thyroid 2007; 17: 923-938

2 Sanders J, Núñez Miguel R, Furmaniak J, Rees Smith B. TSH receptor monoclonal antibodies with agonist antagonist and inverse agonist activities. Meth Enzymol 2010; 485: 393-420

3 Furmaniak J, Sanders J, Rees Smith B. Blocking type TSH receptor antibodies. Autoimmun Highlights 2013; 4: 11-26

4 McLachlan SM, Rapoport B. Breaking tolerance to thyroid antigens: changing concepts in thyroid autoimmunity. Endocrine Rev 2014; 35: 59-105

5 Zakarija M, McKenzie JM. Immunoglobulin G inhibitor of thyroid-stimulating antibody is a cause of delay in the onset of neonatal Graves' disease. J Clin Invest 1983; 72: 1352-1356

6 Zakarija M, McKenzie JM, Eidson MS. Transient neonatal hypothyroidism: characterization of maternal antibodies to the thyrotropin receptor. J Clin Endocrinol Metab 1990; 70: 1239-1246

7 Rees Smith B, Sanders J, Evans M, Tagami T, Furmaniak J. TSH receptor - autoantibody interactions. Horm Metab Res 2009; 41: 448-455

8 Evans M, Sanders J, Tagami T, Sanders P, Young S, Roberts E, Wilmot J, Hu X, Kabelis K, Clark J, Holl S, Richards T, Collyer A, Furmaniak J, Rees Smith $B$. Monoclonal autoantibodies to the TSH receptor one with stimulating activity and one with blocking activity obtained from the same blood sample. Clin Endocrinol 2010; 73: 404-412

9 Kamath C, Young S, Kabelis K, Sanders J, Adlan MA, Furmaniak J, Rees Smith B, Premawardhana $L D$. Thyrotropin receptor antibody characteristics in a woman with long-standing Hashimoto's who developed Graves' disease and pretibial myxoedema. Clin Endocrinol 2012; 77: $465-470$

10 Sanders J, Evans M, Premawardhana LDKE, Depraetere H, Jeffreys J, Richards T, Furmaniak J, Rees Smith B. Human monoclonal thyroid stimulating autoantibody. Lancet 2003; 362: 126-128

11 Sanders J, Evans M, Betterle C, Sanders P, Bhardwaja A, Young S, Roberts E, Wilmot J, Richards T, Kiddie A, Small K, Platt H, Summerhayes S, Harris $R$, Reeve M, Coco G, Zanchetta R, Chen S, Furmaniak J, Rees Smith B. A human monoclonal autoantibody to the thyrotropin receptor with thyroid-stimulating blocking activity. Thyroid 2008; 18: 735-746

12 Yoshida T, Ichikawa $Y$, Ito K, Homma M. Monoclonal antibodies to the thyrotropin receptor bind to a 56-kDa subunit of the thyrotropin receptor and show heterogeneous bioactivities. J Biol Chem 1988; 263: 16341-16347

13 Akamizu T, Moriyama K, Miura M, Saijo M, Matsuda F, Nakao K. Characterization of recombinant monoclonal antithyrotropin receptor antibodies (TSHRAbs) derived from lymphocytes of patients with Graves' disease: epitope and binding study of two stimulatory TSHRAbs. Endocrinol 1999; 140: 1594-1601

14 Valente WA, Vitti P, Yavin Z, Yavin E, Rotella CM, Grollman EF, Toccafondi RS, Kohn LD. Monoclonal antibodies to the thyrotropin receptor: stimulating and blocking antibodies derived from the lymphocytes of patients with Graves' disease. Proc Natl Acad Sci USA 1982; 79 : 6680-6684

15 Kohn LD, Suzuki K, Hoffman WH, Tombaccini D, Marocci C, Shimojo N, Watanabe Y, Amino N, Cho BY, Kohno Y, Hirai A, Tahara K. Characterization of monoclonal thyroid-stimulating and thyrotropin bindinginhibiting autoantibodies from a Hashimoto's patient whose children had intrauterine and neonatal thyroid disease. J Clin Endocrinol Metab 1997; 82: 3998-4009

16 Nakatake N, Sanders J, Richards T, Burne P, Barrett C, Dal Pra C, Presotto $F$, Betterle C, Furmaniak J, Rees Smith B. Estimation of TSH receptor autoantibody serum concentration and affinity. Thyroid 2006; 16 : 1077-1084

17 Sanders J, Oda Y, Roberts SA, Maruyama M, Furmaniak J, Rees Smith B. Understanding the thyrotropin receptor function-structure relationship. In: Davies TF (ed.). Baillière's Clinical Endocrinology \& Metabolism. London: Baillière Tindall; 1997: 11: 451-479

18 Farid NR, Szkudlinski MW. Structural and functional evolution of the thyrotropin receptor. Endocrinol 2004; 145: 4048-4057

19 Vassart G, Pardo L, Costagliola S. A molecular dissection of the glycoprotein hormone receptors. Trends Biochem Sci 2004; 29: 119-126
20 Grossman M, Weintraub BD, Szkudlinski MW. Novel insights into the molecular mechanisms of human thyrotropin action: structural, physiological, and therapeutic implications for the glycoprotein hormone family. Endocr Rev 1997; 18: 476-501

21 Tonacchera M, Ferrarini E, Dimida A, Agretti P, De Marco G, Pinchera A, Sanders J, Evans M, Richards T, Furmaniak J, Rees Smith B. Effects of a thyroid-stimulating human monoclonal autoantibody (M22) on functional activity of LH and FSH receptors. Thyroid 2006; 16: 1085-1089

22 Sanders J, Jeffreys J, Depraetere H, Evans M, Richards T, Kiddie A, Brereton K, Premawardhana LDKE, Chirgadze DY, Núñez Miguel R, Blundell $T L$, Furmaniak J, Rees Smith B. Characteristics of a human monoclonal autoantibody to the thyrotropin receptor: sequence structure and function. Thyroid 2004; 14: 560-570

23 Núñez Miguel R, Sanders J, Sanders P, Young S, Clark J, Kabelis K, Wilmot J, Evans M, Roberts E, Hu X, Furmaniak J, Rees Smith B. Similarities and differences in interactions of thyroid stimulating and blocking autoantibodies with the TSH receptor. J Mol Endocrinol 2012; 49: 137-151

24 Sanders J, Chirgadze DY, Sanders P, Baker S, Sullivan A, Bhardwaja A, Bolton J, Reeve M, Nakatake N, Evans M, Richards T, Powell M, Núñez Miguel R, Blundell TL, Furmaniak J, Rees Smith B. Crystal structure of the TSH receptor in complex with a thyroid-stimulating autoantibody. Thyroid 2007; 17: 395-410

25 Sanders J, Bolton J, Sanders P, Jeffreys J, Nakatake N, Richards T, Evans $M$, Kiddie A, Summerhayes $S$, Roberts E, Núñez Miguel R, Furmaniak $J$, Rees Smith B. Effects of TSH receptor mutations on binding and biological activity of monoclonal antibodies and TSH. Thyroid 2006; 16: $1195-1206$

26 Sanders J, Núñez Miguel R, Bolton J, Bhardwaja A, Sanders P, Nakatake $N$, Evans $M$, Furmaniak J, Rees Smith B. Molecular interactions between the TSH receptor and a thyroid-stimulating monoclonal autoantibody. Thyroid 2007; 17: 699-706

27 Fan $Q R$, Hendrickson WA. Structure of human follicle-stimulating hormone in complex with its receptor. Nature 2005; 433: 269-277

28 Núñez Miguel R, Sanders J, Chirgadze DY, Furmaniak J, Rees Smith B. Thyroid stimulating autoantibody M22 mimics TSH binding to the TSH receptor leucine rich domain: a comparative structural study of protein-protein interactions. J Mol Endocrinol 2009; 42: 381-395

29 Okuda J, Akimizu T, Sugawa H, Matsuda F, Hua L, Mori T. Preparation and characterization of monoclonal antithyrotropin receptor antibodies obtained from peripheral lymphocytes of hypothyroid patients with primary myxedema. J Clin Endocrinol Metab 1994; 79: $1600-1604$

30 Moriyama K, Okuda J, Saijo M, Hattori Y, Kanamoto N, Hataya Y, Matsuda F, Mori T, Nakao K, Akimizu T. Recombinant monoclonal thyrotropin-stimulation blocking antibody (TSBAb) established from peripheral lymphocytes of a hypothyroid patient with primary myxedema. J Endocrinol Invest 2003; 26: 1076-1080

31 Morgenthaler NG, Rim Kim M, Tremble J, Cai Huang G, Richter W, Gupto $M$, Scherbaum WA, McGregor AM, Banga JP. Human immunoglobulin $G$ autoantibodies to the thyrotropin receptor from Epstein-Barr virus-transformed B lymphocytes: characterization by immunoprecipitation with recombinant antigen and biological activity. J Clin Endocrinol Metab 1996; 81: 3155-3161

32 Sanders $P$, Young S, Sanders J, Kabelis K, Baker S, Sullivan A, Evans $M$ Clark J, Wilmot J, Hu X, Roberts E, Powell M, Núñez Miguel R, Furmaniak $J$, Rees Smith B. Crystal structure of the TSH receptor TSHR bound to a blocking-type TSHR autoantibody. J Mol Endocrinol 2011; 46: 81-99

33 Takasu N, Matsushita M. Changes of TSH-stimulation blocking antibody (TSBAb) and thyroid stimulating antibody (TSAb) over 10 years in 34 TSBAb-positive patients with hypothyroidism and in 98 TSAbpositive Graves' patients with hyperthyroidism: reevaluation of TSBAb and TSAb in TSH-receptor-antibody (TRAb)-positive patients. J Thyroid Res 2012; 2012: 182176

34 Sanders J, Jeffreys J, Depraetere H, Richards T, Evans M, Kiddie A, Brereton $K$, Groenen M, Oda Y, Furmaniak J, Rees Smith B. Thyroid-stimulating monoclonal antibodies. Thyroid 2002; 12: 1043-1050

35 Ando T, Latif R, Pritsker A, Moran T, Nagayama Y, Davies TF. A monoclonal thyroid-stimulating antibody. J Clin Invest 2002; 110: 1667-1674

36 Costagliola S, Bonomi M, Morganthaler NG, Van Durme J, Panneels V, Refetoff S, Vassart G. Delineation of the discontinuous-conformational epitope of a monoclonal antibody displaying full in vitro and in vivo thyrotropin activity. Mol Endocrinol 2004; 18: 3020-3034

37 Sanders J, Allen F, Jeffreys J, Bolton J, Richards T, Depraetere H, Nakatake N, Evans M, Kiddie A, Premawardhana LDKE, Chirgadze DY, Núñez Miguel R, Blundell TL, Furmaniak J, Rees Smith B. Characteristics of a monoclonal antibody to the thyrotropin receptor that acts as a powerful thyroid-stimulating autoantibody antagonist. Thyroid 2005; 15 : 672-682 
38 Gilbert J, Gianoukakis A, Salehi S, Moorhead J, Rao P, Kahn MZ, McGregor A, Smith T, Banga JP. Monoclonal pathogenic antibodies to the thyroid stimulating hormone receptor in Graves' disease with potent thyroidstimulating activity but differential blocking activity activate multiple signalling pathways. J Immunol 2006; 176: 5084-5092

39 Chen CR, McLachlan SM, Rapoport B. Suppression of thyrotropin receptor constitutive activity by a monoclonal antibody with inverse agonist activity. Endocrinology 2007; 148: 2375-2382

40 Chen CR, McLachlan SM, Rapoport B. Identification of key amino acid residues in a thyrotropin receptor monoclonal antibody epitope provides insight into its inverse agonist and antagonist properties. Endocrinology 2008; 149: 3427-3434

41 Southgate K, Creagh F, Teece M, Kingswood C, Rees Smith B. A receptor assay for the measurement of TSH receptor antibodies in unextracted serum. Clin Endocrinol (Oxf) 1984; 20: 539-548

42 Rees Smith B, Bolton J, Young S, Collyer A, Weeden A, Bradbury J, Weightman $D$, Perros $P$, Sanders J, Furmaniak $W$. A new assay for thyrotropin receptor autoantibodies. Thyroid 2004; 14: 830-835

43 Hermsen D, Broekcer-Preuss M, Casati M, Camara Mas J, Eckstein A, Gassner D, van Helden J, Inomata K, Jaraush J, Kratzsch J, Mann K, Miyazaki N, Navarro Morena MA, Murakami T, Roth H-J, Yoshimura Noh J, Scherbaum WA, Schott M. Technical evaluation of the first fully automated assay for the detection of TSH receptor autoantibodies. Clin Chim Acta 2009; 401: 84-89

44 Hansel TT, Kropshofer H, Singer T, Mitchell JA, George AJT. The safety and side effects of monoclonal antibodies. Nature Rev Drug Disc 2010; 9: $325-338$

45 Beck A, Wurch T, Bailly C, Corvaia N. Strategies and challenges for the next generation of therapeutic antibodies. Nature Rev Immunol 2010; 10: 345-352

46 Nelson AL, Dhimolea E, Reichert JM. Development trends for human monoclonal antibody therapeutics. Nature Rev Drug Disc 2010; 9: 767-774

47 Furmaniak J, Sanders J, Young S, Kabelis K, Sanders P, Evans M, Clark J, Wilmot J, Rees Smith B. In vivo effects of a human thyroid stimulating monoclonal autoantibody (M22) and a human thyroid-blocking autoantibody (K1-70). Autoimmun Highlights 2012; 3: 19-25

48 Luster M. Present status of the use of recombinant human TSH in thyroid cancer management. Acta Oncol 2006; 45: 1018-1030

49 Fast S, Hegedüs L, Grupe P, Nielsen VE, Bluhme C, Bastholt L, Bonnema SJ. Recombinant human thyrotropin-stimulated radioiodine therapy of nodular goiter allows major reduction of the radiation burden with retained efficacy. J Clin Endocrinol Metab 2010; 95: 3719-3725

50 Fast S, Nielsen VE, Bonnema SJ, Hegedüs L. Dose-dependent acute effects of recombinant human TSH (rhTSH) on thyroid size and function: comparison of $0.1,0.3$ and $0.9 \mathrm{mg}$ of rhTSH. Clin Endocrinol 2010; 72: 411-416

51 Bonnema SJ, Hegedüs L. Radioiodine therapy in benign thyroid diseases: effects, side effects and factors affecting therapeutic outcome. Endocrine Rev 2012; 33: 920-980

52 Pearce EN. Diagnosis and management of thyrotoxicosis. Br Med J 2006; 332: 1369-1373

53 Laurberg $P$. Remission of Graves' disease during anti-thyroid drug therapy: time to reconsider the mechanism? Eur J Endocrinol 2006; 155: 783-786

54 Bahn RS, Burch HB, Cooper DS, Garber JR, Greenlee MC, Klein I, Laurberg P, McDougall IR, Montori VM, Rivkees SA, Ross DS, Sosa JA, Stan MN. Hyperthyroidism and other causes of thyrotoxicosis: management guidelines of the American Thyroid Association and American Association of Clinical Endocrinologists. Thyroid 2011; 21: 593-646

55 Burch HB, Burman KD, Cooper DS. A 2011 survey of clinical practice patterns in the management of Graves' disease. J Endocrinol Metab 2012; 97: 4549-4558

56 Arey BJ. Allosteric modulators of glycoprotein hormone receptors: discovery and therapeutic potential. Endocr 2008; 34: 1-10

57 Davies TF, Ali MJ, Latif R. Allosteric modulators hit the TSH receptor. Endocrinol 2014; 155: 1-5

58 Gerrits M, Mannaerts B, Kramer H, Addo S, Hanssen R. First evidence of ovulation induced by oral $\mathrm{LH}$ agonists in healthy female volunteers of reproductive age. J Clin Endocrinol Metab 2013; 98: 1558-1566

59 van Koppen CJ, de Gooyer ME, Karstens W-J, Plate R, Conti PGM, van Achterberg TAE, van Amstel MGA, Brands JHGM, Wat J, Bert RJW, Lane JRD, Miltenburg AMM, Timmers CM. Mechanism of action of a nanomolar potent, allosteric antagonist of the thyroid-stimulating hormone receptor. Brit J Pharmacol 2012; 165: 2314-2324
60 Neumann S, Huang $W$, Titus S, Krause G, Kleinau G, Alberobello AT Zheng W, Southall NT, Inglese J, Austin CP, Celi FS, Gavrilova O, Thomas CJ, Raaka BM, Gershengorn MC. Small-molecule agonists for the thyrotropin receptor stimulate thyroid function in human thyrocytes and mice. Proc Natl Acad Sci USA 2009; 106: 12471-12476

61 Neumann S, Nir EA, Eliseeva E, Huang W, Marugan J, Xiao J, Dulcey AE, Gershengorn MC. A selective TSH receptor antagonist inhibits stimulation of thyroid function in female mice. Endocrinol 2014; 155: 310-314

62 Klubo-Gwiezdzinska J, Wartofsky L. Thyroid emergencies. Med Clin N Am 2012; 96: 385-403

63 Kumar S, Schiefer R, Coenen MJ, Bahn RS. A stimulatory thyrotropin receptor antibody (M22) and thyrotropin increase interleukin-6 expression and secretion in Graves' orbital preadipocyte fibroblasts. Thyroid 2010; 20: 59-65

64 Iyer S, Bahn R. Immunopathogenesis of Graves' ophthalmopathy: the role of the TSH receptor. Best Pract Res Clin Endocrinol Metab 2012; 26: 281-289

65 Krieger CC, Gershengorn MC. A modified ELISA accurately measures secretion of high molecular weight hyaluronan (HA) by Graves' disease orbital cells. Endocrinol 2014; 155: 627-634

66 Kumar S, Nadeem S, Stan MS, Coenen M, Bahn RS. A stimulatory TSH receptor antibody enhances adipogenesis via phosphoinositide 3-kinase activation in orbital preadipocytes from patients with Graves' ophthalmopathy. J Mol Endocrinol 2011; 46: 155-163

67 Tanda ML, Piantanida E, Bartalena L. Treating Graves' orbitopathy: where are we? Endocr 2012; 41: 167-168

68 Smith HB, Porteous C, Bunce C, Bonstein K, Hickey J, Dayan CM, Adams $G$, Rose GE, Ezra DG. Description and evaluation of the first national patient and public involvement day for thyroid eye disease in the United Kingdom. Thyroid 2014; 24: 1400-1406

69 El Fassi D, Nielsen CH, Hasselbalch HC, Hegedüs $L$. The rationale for B lymphocyte depletion in Graves' disease. Monoclonal anti-CD20 antibody therapy as a novel treatment option. Eur J Endocrinol 2006; 154: 623-632

70 El Fassi D, Banga JP, Gilbert JA, Padoa C, Hegedüs L, Nielsen CH. Treatment of Graves' disease with rituximab specifically reduces the production of thyroid stimulating antibodies. Clin Immunol 2009; 130: $252-258$

71 Núñez Miguel R, Sanders J, Sanders P, Young S, FurmaniakJ, Rees Smith B. Glycosylation pattern analysis of glycoprotein hormones and their receptors. Eur Thyroid J 2014; 3 (Suppl 1): 84

72 Chen CR, Tanaka K, Chazenbalk GD, McLachlan SM, Rapoport B. A full biological response to autoantibodies in Graves' disease requires a disulfide-bonded loop in the thyrotropin receptor $\mathrm{N}$ terminus homologous to a laminin epidermal growth factor-like domain. J Biol Chem 2001; 276: 14767-14772

73 Jiang X, Liu H, Chen X, Chen PH, Fischer D, Sriraman V, Yu HN, Arkinstall $S$, He X. Structure of follicle-stimulating hormone in complex with the entire ectodomain of its receptor. Proc Natl Acad Sci USA 2012; 109: $12491-12496$

74 Sanders J, Núñez Miguel R, Sanders P, Young S, FurmaniakJ, Rees Smith B. Mechanism of TSHR activation by TSH and thyroid stimulating antibodies. Eur Thyroid J 2014; 3 (Suppl 1): 82

75 Krause G, Kreuchwig A, Kleinau G. Extended and structurally supported insights into extracellular hormone binding, signal transduction and organization of the thyrotropin receptor. PLoS ONE 2012; 7: e52920

76 Duprez L, Parma J, Costagliola S, Hermans J, Van Sande J, Dumont JE, Vassart G. Constitutive activation of the TSH receptor by spontaneous mutations affecting the N-terminal extracellular domain. FEBS Lett 1997; 409: 469-474

77 Grzesik P, Teichmann A, Furkert J, Rutz C, Wiesner B, Kleinau G, Schülein $R$, Gromoll J, Krause G. Differences between lutropin-mediated and choriogonadotropin-mediated receptor activation. FEBS J 2014; 281: 1479-1492

78 Jaeschke H, Schaarschmidt J, Günther R, Mueller S. The hinge region of the TSH receptor stabilizes ligand binding and determines different signalling profiles of human and bovine TSH. Endocrinology 2011; 152: 3986-3996

79 Schaarschmidt J, Huth S, Meier R, Paschke R, Jaeschke H. Influence of the hinge region and its adjacent domains on binding and signalling patterns of the thyrotropin and follitropin receptor. PLoS One 2014; 9: e111570

80 Horimoto M, Petersen VB, Pegg CAS, Fukuma N, Wabayashi N, Kiso $Y$, Furmaniak J, Rees Smith B. Production and characterization of a human monoclonal thyroid peroxidase autoantibody. Autoimmunity 1992; 14: $1-7$ 
81 De Lano WL. The Pymol molecular graphics system. DeLano Scientific; San Carlos, CA: 2002http://pymol.sourceforge.net/

82 Jäschke H, Neumann S, Moore S, Thomas CJ, Colson A-O, Costanzi S, Kleinau G, Jiang J-K, Paschke R, Raaka BM, Krause G, Gershengorn MC. A low molecular weight agonist signals by binding to the transmembrane domain of thyroid-stimulating hormone receptor (TSHR) and luteinizing hormone/chorionic gonadotropin receptor (LHCGR). J Biol Chem 2006; 281: 9841-9844
83 Latif R, Ali MR, Ma R, David M, Morshed SA, Ohlmeyer M, Felsenfeld DP, Lau Z, Mezei M, Davies TF. New small molecule agonists to the thyrotropin receptor. Thyroid 2015; 25: 51-62

84 Neumann S, Kleinau G, Costanzi S, Moor S, Jiang J-K, Raaka BM, Thomas CJ, Krause G, Gershengorn MC. A low-molecular-weight antagonist for the human thyrotropin receptor with therapeutic potential for hyperthyroidism. Endocrinology 2008; 149: 5945-5950 